Acta Crystallographica Section B

Structural

Science

ISSN 0108-7681

Richard E. Marsh, ${ }^{a}$ Moshe Kapon, ${ }^{b}$ Shengzhi $\mathrm{Hu}^{\mathrm{c}}$ and Frank H. Herbstein ${ }^{b_{*}}$

aThe Beckman Institute, California Institute of Technology, Pasadena, CA 91125, USA, Institute of Technology, Haifa 32000, Israel, and ' Department of Chemistry, Xiamen University, Xiamen, Peoples' Republic of China

Correspondence e-mail: chr03fh@tx.technion.ac.il
${ }^{\mathbf{b}}$ Department of Chemistry, Technion-Israel

\section{Some 60 new space-group corrections}

Some 60 examples of crystal structures are presented which can be better described in space groups of higher symmetry than used in the original publications. These are divided into three categories: (A) incorrect Laue group (33 examples), (B) omission of a center of symmetry (22 examples), (C) omission of a center of symmetry coupled with a failure to recognize systematic absences (nine examples). Category A errors do not lead to significant errors in molecular geometry, but these do accompany the two other types of error. There are 19 of the current set of examples which have publication dates of 1996 or later. Critical scrutiny on the part of authors, editors and referees is needed to eliminate such errors in order not to impair the role of crystal structure analysis as the chemical court of last resort.

\section{Introduction}

Following earlier papers (e.g. Baur \& Tillmanns, 1986; Marsh \& Herbstein, 1988; Baur \& Kassner, 1992; Marsh \& Bernal, 1995; Marsh, 1995, 1997, 1999; Herbstein, 1997; Herbstein \& Marsh, 1998), here we report and discuss more examples where crystal structures have been described in space groups of unnecessarily low symmetry. The methodology used has been described by Herbstein \& Marsh (1998) and elsewhere. While in most instances the atom connectivity is not affected, and the chemical identity of the compound is not in question, use of the wrong space group often leads to unrealistic bond lengths and angles. Moreover, many physical properties of crystals are symmetry dependent and contradictions may appear if an error has been made in the determination of the space group. We divide our examples into three categories.

In 'Category $A$ ' errors the Laue group has not been assigned correctly. For the most common crystal systems, triclinic, monoclinic or orthorhombic, the Laue group defines the shape of the unit cell and the possibility of such an error can be checked using the tools of the reduced cell ${ }^{1}$ and the Niggli matrix as soon as cell dimensions are available; for the remaining crystal systems, tetragonal, trigonal, hexagonal and cubic, such checking is not fruitful. We particularly note that the true errors in cell dimensions (especially angles) can be far larger than assigned standard uncertainties (Taylor \& Kennard, 1986; Marsh, 1995; Herbstein, 2000), so that a cell
Received 2 June 2001 Accepted 12 October 2001 
that appears to be oblique beyond experimental error may in fact be rectilinear. In any event, confirmation that the Laue symmetry is truly in error can only be obtained before the final structure has been determined from a comparison of intensities of possibly related reflections, for example, by evaluating $R$ (merge) for the various possibilities. Such an assessment of the symmetry of the intensity-weighted reciprocal lattice can only be made by a secondary investigator if a list of observed structure factors is available, which (unfortunately) is usually not the case. In general, a secondary investigator must depend on the final list of atom coordinates (and, if they are available, the $U^{i j}$, s) for checking. These parameters should provide conclusive proof, one way or the other, because the symmetry of the final structure must always agree with the symmetry of the intensity-weighted reciprocal lattice within their mutual standard deviations (Schomaker \& Marsh, 1979). As a corollary, the derived results, such as molecular dimensions, are effectively unchanged when a structure is refined in an unnecessarily low Laue symmetry.

In 'Category B' errors the Laue symmetry has been determined correctly but, where systematic absences (reflection

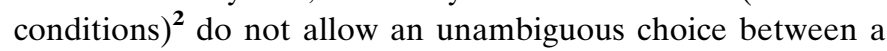
centrosymmetric and a non-centrosymmetric space group, the authors have chosen the non-centrosymmetric one and this may well require further consideration. In principle, the choice can be made as soon as intensity data are available, either by statistical tests of the intensities or, if heavy atoms are present, by examining Friedel-related reflections. However, statistical tests are often unreliable (Hargreaves, 1955; Marsh, 1981) and the presence of heavy atoms may lead to absorption errors that can confuse Friedel relationships. Accordingly, a check for centrosymmetry is best made after the structure has been solved, by examining the atom coordinates or, perhaps, by viewing a drawing of the entire structure. In this regard we wish to emphasize that the large correlations arising from the refinement of an approximately centrosymmetric model in a non-centrosymmetric space group relate primarily to the antisymmetric aspects of the model, the deviations from centrosymmetry, so that symmetrizing the structure (whatever the true space group) should lead to quite reliable average coordinates. We have found this to be so in almost all the structures we have studied, the revised, centrosymmetric structure leading to bond lengths and angles in close agreement with standard values even when the unrevised (noncentrosymmetric) values are highly discrepant; differences in coordinates can be comparatively large (say, up to ten times the reported s.u.'s) because of the problem of near-singularity. Further refinement in the centrosymmetric space group would generally be needed to obtain optimal precision.

We have found one example which belongs to both Categories A and B. This is FISMUP, which is changed from orthorhombic to hexagonal, and has a center added. We have placed it at the end of Category A.

\footnotetext{
$\overline{\mathbf{2}}$ 'Conditions limiting possible reflections', used in International Tables for Crystallography, are formally preferable, but long.
}

In 'Category C' errors an erroneous space group was inferred because the reflection conditions had not been correctly determined (Marsh, 1995, see pp. 900-901). Category $\mathrm{C}$ is a subgroup of Category $\mathrm{B}$, where the addition of a center of symmetry results in changes in the reflection conditions (screw axes or glide planes are also added). The first step towards correcting such errors in space-group determination is by careful inspection of the reflection conditions; here it is necessary to have access to the $F(\mathrm{obs})$ lists and, as noted, these are not always available. Even when the $F($ obs) values are available the secondary investigator may face severe problems, particularly when the deviations from centrosymmetry are small and the apparent violations of the reflection conditions are weak. Are these violations real or are they due to wavelength contamination, multiple reflection (the Renninger effect) or background problems? How reliable are the error estimates (if they are available) for these weak intensities? (This latter question is particularly cogent in the assessment of CCD data.) Was a small twin component present? What criteria were used in determining whether or not a category of reflections is truly absent? These are vexing questions, beyond the power of the secondary investigator (and perhaps the primary investigator as well) to answer. We have accessed the $F$ list for some Category $\mathrm{C}$ examples, and treated others in the same way as Category B. If the deviations from centrosymmetry are small, and the improvement in molecular geometry on symmetrizing the structure is large, we have opted for the higher-symmetry description, knowingly flouting the traditional lore that a single violation of a systematic absence condition is adequate cause for rejecting the corresponding symmetry element. Among previous examples of this type are 2-hydroxybenzimidazole (Herbstein \& Kapon, 1985) and 1,2,7a-trihydroxy-2-methylperhydro-1phosphaindene 1-oxide (Marsh, 1994); the space group was corrected from $P 2_{1}$ to $P 2_{1} / n$ for both crystals.

We add that many examples in our Category A list also entail the presumption of systematic absences. For example, the change from a triclinic to a $\mathrm{C}$-centered monoclinic space group may require (besides the $\mathrm{C}$-centering conditions, which fall at half-integral nodes of the triclinic reciprocal lattice and are not accessed under normal conditions) systematic absences due to glide planes, whose exact form in the triclinic reciprocal lattice depends on the relation between triclinic and monoclinic cells.

\section{Experimental}

Examples have been found by perusal of recent issues of journals, many by chance. In most cases the coordinates were obtained from the Cambridge Structural Database (CSD; Cambridge Structural Database, 2001), which we follow for the numbering of atoms except where noted. We have included hydrogen parameters only exceptionally. Other sources of supplementary material are noted, such as the office of the Editor of the Bulletin of The Chemical Society of Japan (BCSJ). We have recovered supplementary tables of $F(\mathrm{obs})$ values for a few examples, usually to establish reciprocal 
Table 1

The corrections have been ordered as follows: first by category, second by original space group ( 1 to 230 ), third by revised space group, and finally by REFCODE (alphabetically).

\begin{tabular}{|c|c|c|c|c|}
\hline No. & Refcode & $\begin{array}{l}\text { Original } \\
\text { space group }\end{array}$ & $\begin{array}{l}\text { Revised } \\
\text { space group }\end{array}$ & Reference \\
\hline \multicolumn{5}{|c|}{ Category A: Change in Laue group } \\
\hline 1 & None & $P 1$ & $C 2$ & $\begin{array}{l}\text { Makedonopoulou et al. } \\
\quad(2000)\end{array}$ \\
\hline 2 & None & $P 1$ & $C 2$ & $\begin{array}{l}\text { Makedonopoulou et al. } \\
\quad(2000)\end{array}$ \\
\hline 3 & LEKKUH & $P \overline{1}$ & $P 2_{1} / c$ & Katano et al. (1998) \\
\hline 4 & PENNAX & $P \underline{\overline{1}}$ & $P 2_{1} / n$ & Lee et al. (1993) \\
\hline 5 & RIJQOQ & $P \underline{\overline{1}}$ & $P 2_{1} / n$ & Filippou et al. (1997) \\
\hline 6 & CICTUD & $P \overline{1}$ & $C 2 / c$ & Ito et al. (1999) \\
\hline 7 & DEMWOH & $P \underline{1}$ & $C 2 / c$ & Nakashima et al. (1985) \\
\hline 8 & FIYGOJ & $P \overline{1}$ & $C 2 / c$ & Taniguchi et al. (1987) \\
\hline 9 & KUSLUF & $P \overline{1}$ & $C 2 / c$ & Nakano et al. (1992) \\
\hline 10 & RICLOE & $P \overline{1}$ & $C 2 / c$ & Cabeza et al. (1996) \\
\hline 11 & TILMEG & $P \underline{\overline{1}}$ & $C 2 / c$ & Taube et al. (1996) \\
\hline 12 & VEWPOC10 & $P \overline{1}$ & $C 2 / c$ & Mikuriya et al. (1993) \\
\hline 13 & WABKOZ & $P \overline{1}$ & $C 2 / c$ & Fawcett et al. (1992) \\
\hline 14 & YATZOI10 & $P \overline{1}$ & $C 2 / c$ & Mikuriya et al. (1996) \\
\hline 15 & TUMLES & $P 2_{1}$ & $P 2_{1} 2_{1} 2_{1}$ & Urban et al. (1996) \\
\hline 16 & CECMAY10 & $P 2_{1}$ & $C 222_{1}$ & Harata et al. (1987) \\
\hline 17 & JIGREW & $P 2_{1}$ & $C 222_{1}$ & Nogami et al. (1990) \\
\hline 18 & VOGLUY & $P 2_{1}$ & $\mathrm{Cmc2} 2_{1}$ & Kitajima et al. (1991) \\
\hline 19 & WIFFOG & $\mathrm{Cm}$ & Fmm2 & Gradoz et al. (1994) \\
\hline 20 & AZPADO & $\mathrm{Cm}$ & $R 3 m$ & Jogun et al. (1978) \\
\hline 21 & AZPADS & $\mathrm{Cm}$ & $R 3 m$ & Jogun et al. (1978) \\
\hline 22 & None & $B b$ & $R 3 c$ & Makitova et al. (1989) \\
\hline 23 & NEGXOM & $P 2_{1} / c$ & Pccn & Michalska et al. (1996) \\
\hline 24 & YIVWOP & $C 2 / c$ & $I 4_{1} / a$ & Selent \& Ramm (1995) \\
\hline 25 & TONWUO & $C 2 / c$ & $I 4_{1} /$ acd & Wei et al. (1996) \\
\hline 26 & PYRDNO10 & $C 222_{1}$ & $P 4_{1} 2_{1} 2$ & Ülkü et al. (1971) \\
\hline 27 & ROBJEX & $P 4_{1}$ & $P 4_{1} 2_{1} 2$ & Hahn et al. (1996) \\
\hline 28 & JUNNAH & $R 3$ & $P 2_{1} 3$ & $\begin{array}{l}\text { Brand \& Vahrenkamp } \\
\quad(1992 a, b)\end{array}$ \\
\hline 29 & TAZPAD & $R \underline{3}$ & $R 3 m$ & Fluck et al. (1977) \\
\hline 30 & POJKAA & $P \overline{3}$ & $P 6_{3} / m$ & Michelin et al. (1994) \\
\hline 31 & FABTAD10 & $R \overline{3}$ & $R \overline{3} c$ & Fait et al. (1991) \\
\hline 32 & FISMUP & $\mathrm{Cmc2} 2_{1}$ & $\mathrm{~Pb}_{3} / \mathrm{mcm}$ & Prozorovskii et al. (1987) \\
\hline Note & None & $C 2 / c$ & $\mathrm{Cccm}$ & $\begin{array}{l}\text { Yuranov \& } \\
\quad \text { Dunaeva (1989) }\end{array}$ \\
\hline
\end{tabular}

Category B: Add a center of symmetry

$\begin{array}{lllll}33 & \text { YOJBUU } & P 2_{1} & P 2_{1} / m & \text { Balakaeva } \text { et al. }(1994) \\ 34 & \text { HEFSIU } & P c & P 2 / c & \text { Shubnell } \text { et al. }(1994) \\ 35 & \text { RACFEG } & C m & C 2 / m & \text { Kitazawa } \text { et al. }(1992) \\ 36 & \text { CHXCUB } & C m & C 2 / m & \text { Kamisawa } \text { et al. }(1981) \\ 37 & \text { FOHDUB } & C m & C 2 / m & \text { Hörlein } \text { et al. }(1987) \\ 38 & \text { KOYXOL } & C m & C 2 / m & \text { Calov } \text { et al. }(1991) \\ 39 & \text { PASQAB } & C m & C 2 / m & \text { Konarev } \text { et al. }(1997) \\ 40 & \text { VOKKIP } & C m & C 2 / m & \text { Sysoeva } \text { et al. }(1990) \\ 41 & \text { POWYUV } & C c & C 2 / c & \text { Le Stang } \text { et al. }(1998) \\ 42 & \text { RIDPID } & A a & C 2 / c & \text { Aizawa } \text { et al. }(1995) \\ 43 & \text { ZAWSUL } & C c & C 2 / c & \text { Rieger } \text { et } \text { al. }(1995) \\ 44 & \text { ZEDCUG } & C c & C 2 / c & \text { Yasuda } \text { et al. }(1994) \\ 45 & \text { None } & C c & C 2 / c & \text { Asari } \text { et al. }(2001) \\ 46 & \text { None } & P n a 2_{1} & P n m a & \text { Shibahara } \text { et al. }(1995) \\ 47 & \text { FOZPAL } & P n 2_{1} a & P n m a & \text { Steil } \text { et al. }(1988) \\ 48 & \text { KISNAB } & P n a 2_{1} & P n m a & \text { Constable } \text { et al. }(1991) \\ 49 & \text { YUFXIG } & P c 2_{1} n & P n m a & \text { Mathur } \text { et al. }(1995) \\ 50 & \text { ZUFDIN } & P 4_{2} & P 4_{2} / m & \text { Kido } \text { et al. }(1995) \\ 51 & \text { LAKRIY } & P 3 & P \overline{3} & \text { Joachim } \text { et al. }(1993) \\ 52 & \text { LAKROE } & P 3 & P \overline{3} & \text { Joachim } \text { et al. }(1993) \\ 53 & \text { ZATGIK } & R 3 & R \overline{3} & \text { Ma } \text { et al. }(1994) \\ 54 & \text { PAMCOV } & P 6_{3} & P 6_{3} / m & \text { Abe } \text { et } \text { al. }(1992)\end{array}$

Category C: Add center of symmetry and systematic absences

$\begin{array}{lllll}55 & \text { KERGET } & P 2_{1} & P 2_{1} / n & \text { Shima } \text { et al. }(1989) \\ 56 & \text { LEVJUR } & P 2_{1} & P 2_{1} / c & \text { Tatsumi } \text { et al. }(1994)\end{array}$

Table 1 (continued)

\begin{tabular}{lllll}
\hline No. & Refcode & $\begin{array}{l}\text { Original } \\
\text { space group }\end{array}$ & $\begin{array}{l}\text { Revised } \\
\text { space group }\end{array}$ & Reference \\
\hline 57 & ZEDDAN & $P 2_{1}$ & $P 2_{1} / c$ & Yasuda et al. $(1994)$ \\
58 & CADKUN & $P n$ & $P 2_{1} / n$ & Yagyu et al. $(1998)$ \\
59 & KUSLOZ & $P n$ & $P 2_{1} / n$ & Kita et al. $(1992)$ \\
60 & TOSSAV & $P c$ & $P 2_{1} / c$ & Aizawa et al. $(1996)$ \\
61 & VOZVIP & $P c$ & $P 2_{1} / c$ & Nakazumi et al. $(1992)$ \\
62 & NALCIM & $P 2_{1} 2_{1} 2_{1}$ & $P n m a$ & Garcia et al. $(1996)$ \\
63 & DIXVOV & $P c a 2_{1}$ & $P b c a$ & Berges et al. $(1985)$ \\
\hline
\end{tabular}

lattice symmetry; refinement of the revised structure was carried out in two cases. Preliminary identification of possibly erroneous space groups was by visual inspection of cell dimensions and atom coordinates, and/or of published structural drawings. The fundamentals for transforming axes and coordinates are given in International Tables for Crystallography (Arnold, 1983); see also International Tables for $X$ ray Crystallography (1965). The general (affine) transformation of the coordinate system consists of two parts, a linear part (implying a change of orientation, or lengths, or both of the basis vectors) and a shift of origin. The matrix $\mathbf{P}$ of the linear part and the column $p$, containing the components of the shift vector $p$, define the transformation uniquely. It is represented by the symbol $(\mathbf{P}, p)$. In practice we have found it more transparent to give the transformation matrix for cell axes from the original to the revised cell, followed by the origin shift (if required) in the revised cell. The 'quality of fit' describing the agreement of the revised space group with the reported coordinates is given in Herbstein \& Marsh (1998). The contents are summarized in Table 1. Lists of revised coordinates have been submitted to the CSD and are included as material for deposition (numbered as Table $1 \mathrm{~S}$ etc. according to the index number of the entry). ${ }^{3}$

\section{Category A: change in Laue group}

\section{1. (1) and (2): REFCODES not yet assigned}

Two inclusion complexes of $\beta$-cyclodextrin with the aliphatic monoacids tridecanoic acid and $(Z)$-tetradec-7-enoic acid are reported: $2 \mathrm{C}_{42} \mathrm{H}_{70} \mathrm{O}_{35} \cdot \mathrm{C}_{13} \mathrm{H}_{26} \mathrm{O}_{2} \cdot 19.5 \mathrm{H}_{2} \mathrm{O}$ (1) and $2 \mathrm{C}_{42} \mathrm{H}_{70} \mathrm{O}_{35} \cdot \mathrm{C}_{14} \mathrm{H}_{26} \mathrm{O}_{2} \cdot 14.9 \mathrm{H}_{2} \mathrm{O}$ (2), see Makedonopoulou et al. (2000).

These structures were reported as triclinic, space group $P 1$, $Z=1$ (for formulae given above); (1): $a=15.654$ (6), $b=$

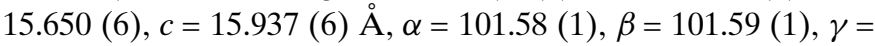
$103.58(1)^{\circ} ; \quad(2): a=15.6259(9), \quad b=15.623(1), \quad c=$ 15.935 (1) $\AA$, $\alpha=101.547$ (2), $\beta=101.555$ (2), $\gamma=103.642$ (2). The equivalences of $a$ with $b$ and of $\alpha$ with $\beta$ suggest the Ccentered monoclinic cells: $a=19.363, b=24.597, c=15.937 \AA$, $\alpha=89.99, \beta=108.95, \gamma=90.02^{\circ}$ for (1), and $a=19.316, b=$ $24.564, c=15.935 \AA, \alpha=89.99, \beta=108.90, \gamma=90.01^{\circ}$ for $(2)$ (transformation matrix, 110, $\overline{1} 10,001)$. In each case the two $\beta$ -

\footnotetext{
${ }^{3}$ Supplementary data for this paper are available from the IUCr electronic archives (Reference: BM0047). Services for accessing these data are described at the back of the journal.
} 
cyclodextrin molecules in the triclinic cell are related, within $0.02 \AA$, by the twofold axis of space group $C 2$; most of the water molecules are also paired across this axis, even though the majority have fractional occupation parameters. In each complex the guest molecule is described as disordered over two orientations with approximate occupancies of $50 \%$ and with very large $U_{\text {eq }}$ values (r.m.s. displacements, $0.6-1.0 \AA$ ); for them, the match with $C_{2}$ symmetry is relatively poor. The structure solutions for these compounds (in the triclinic cells) were by 'isomorphous molecular replacement' based on the 3,5-dimethylbenzoic acid (YOVVIO; Rontoyianni \& Mavridis, 1994) and the 4-tert-butyltoluene (KUTJUE; Mavridis \& Hadjoudis, 1992) channel inclusion complexes of $\beta$-cyclodextrin. The structures of YOVVIO and KUTJUE have already been revised from $P 1$ to $C 2$ (Herbstein \& Marsh, 1998).

\section{2. (3) LEKKUH: 1,7,13,19,25-pentathio[1.5](2,5)-thiophe-} nophane, $\mathrm{C}_{20} \mathrm{H}_{10} \mathrm{~S}_{10}$ (Katano et al., 1998)

This compound was reported in space group $P \overline{1}, Z=4[a=$ 6.0440 (7), $b=17.025$ (3), $c=22.726$ (4) $\AA, \alpha=90.003$ (8), $\beta=$ $\left.90.014(8), \gamma=85.967(9)^{\circ}\right]$. The crystallographic results are not described in any detail and no comment is made about the choice of triclinic cell with two $90^{\circ}$ angles ( $c$ normal to $a, b$ ). Coordinates were not included but have been obtained from BCSJ 71052. After the axes are reoriented to obtain a conventional monoclinic cell, the two independent molecules in $P \overline{1}$ can be matched across a $c$-glide plane within r.m.s. deviations of $\sim 0.005 \AA$. The transformation matrix is $(100$; 001; 010), giving the revised cell as $a=6.044, b=22.726, c=$ $17.025 \AA, \beta=94.033^{\circ}, Z=4$, space group $P 2_{1} / c$.

\section{3. (4) PENNAX: meso-tetraphenylporphyrinatothallium(III) cyanide, $\mathrm{C}_{45} \mathrm{H}_{28} \mathrm{~N}_{5} \mathrm{Tl}$, $\mathrm{Tl}(\mathrm{tpp}) \mathrm{CN}$ (Lee et al., 1993)}

This compound was reported as triclinic, $a=10.003$ (3), $b=$ 16.231 (7), $c=21.277$ (8) ̊, $\alpha=89.98$ (3), $\beta=90.57$ (3), $\gamma=$ $90.31(3)^{\circ}, Z=4$, space group $P \overline{1}$. However, the coordinates of the two purportedly independent molecules are related by $x(\mathrm{I})=0.499(6)-x(\mathrm{II}), y(\mathrm{I})=0.500(1)+y(\mathrm{II}), z(\mathrm{I})=0.500(2)$ $-z$ (II) (i.e. $\frac{1}{2}-x, \frac{1}{2}+y, \frac{1}{2}-z$ ), which are relations between symmetry-related positions in space group $P 2_{1} / n$. The corresponding cell parameters are as above with $\alpha$ and $\gamma$ set equal to $90^{\circ}$. Thus we have assumed that there is a substantial error $\left(\sim 0.3^{\circ}\right)$ in $\gamma$. This is another example where it is the overall symmetry of the structure rather than the details of the cell dimensions that determines the true structure.

\section{4. (5) RIJQOQ: cis-bromo-dicarbonyl-bis(diisopropylami- ne)carbyne-bis(dimethylphenylphosphine)chromium, $\mathrm{C}_{25} \mathrm{H}_{36} \mathrm{BrCrNO}_{2} \mathrm{P}_{2}$ (Filippou et al., 1997)}

This compound was reported in space group $P \overline{1}, Z=4$, with cell dimensions $a=10.084$ (2), $b=16.340$ (3), $c=17.351$ (3) $\AA$, $\alpha=89.89$ (2), $\beta=89.87$ (2), $\gamma=89.98$ (2) ${ }^{\circ}$. The authors remark 'The crystal of [this compound] is pseudo orthorhombic. However, the intensity statistics show no higher symmetry than a center of inversion. Each unit cell...contains two independent molecules'. The coordinates of the two purportedly independent molecules are related (in the reported triclinic cell) by $x(\mathrm{I})=0.4999(5)-x(\mathrm{II}), y(\mathrm{I})=0.5000(2)-y(\mathrm{II})$, $z(\mathrm{I})=-0.5001$ (4) $+z$ (II) $\left(\right.$ i.e. $\left.\frac{1}{2}-x, \frac{1}{2}-y, \frac{1}{2}+z\right)$, which are relations between symmetry-related molecules in space group $P 2_{1} / n$ after interchange of $b$ and $c$ (revised cell $a=10.084, b=$ $17.351, c=16.340 \AA$, $\alpha=90.11, \beta=90.02, \gamma=89.87^{\circ}$; transformation matrix $100 ; 001 ; 0 \overline{1} 0)$. Although the angle $\beta$ is very close to $90^{\circ}$, the coordinates show no symmetry higher than monoclinic. The systematic absences ' 001 for $l$ odd, $h k 0$ for $h+$ $k$ odd' in the triclinic description were apparently not recognized.

\section{5. (6) CICTUD: $\left\{\left[(\mathrm{tpa}) \mathrm{Ni} i^{\prime \prime}(\mu-\mathrm{OH})_{2} \mathrm{Ni}^{\prime \prime}(\mathrm{tpa})\right]\left(\mathrm{ClO}_{4}\right)_{2}\right]$-- 2MeOH) (tpa = tris(2-pyridylmethyl)amine), $\mathrm{C}_{38} \mathrm{H}_{46} \mathrm{Cl}_{2} \mathrm{~N}_{8} \mathrm{Ni}_{2} \mathrm{O}_{12}$ (Ito et al., 1999)}

This structure was reported as triclinic, $P \overline{1}, Z=2 ; a=$ 14.679 (7), $b=14.728$ (8), $c=13.626$ (8) $\AA$, $\alpha=122.65$ (3), $\beta=$ $111.92(4), \gamma=90.02(5)^{\circ}$. If the authors had considered the reduced cell, $a=13.626, b=13.640, c=14.679 \AA$ А, $\alpha=68.08, \beta=$ $68.08, \gamma=65.39^{\circ}$, they might have noted the aac $\alpha \alpha \gamma$ form and been suspicious of higher symmetry. The triclinic cell can be transformed to a $C$-centered monoclinic cell ${ }^{4}(a=22.946, b=$ 14.728, $c=14.679 \AA$ А $\left.\alpha=89.98, \beta=116.33, \gamma=90.06^{\circ} ; Z=4\right)$; the transformation matrix is $(012,0 \overline{1} 0,100)$. Coordinates, not published by Ito et al. (1999) but obtained from BCSJ 72002, can be similarly transformed so as to conform with space group $C 2 / c$. The original triclinic unit cell contains two independent metal complexes, on separate centers of symmetry; the revised monoclinic cell contains four complexes on equivalent centers, Wyckoff positions (c). The two independent sets of perchlorate ions lie on twofold axes, Wyckoff positions $(e)$.

\section{6. (7) DEMWOH: bis(benzonitrile- $N$ )-tetrakis $\left(\mu^{2}\right.$ - trichloroacetato-O, $\mathrm{O}^{\prime}$ )dicopper(II), $\mathrm{C}_{22} \mathrm{H}_{10} \mathrm{Cl}_{12} \mathrm{Cu}_{2} \mathrm{~N}_{2} \mathrm{O}_{8}$ (Nakashima et al., 1985)}

This structure was reported in $P \overline{1}, Z=2[a=12.780(1), b=$ 16.064 (1), $c=10.130$ (1) $\AA, \alpha=108.39$ (1), $\beta=113.34$ (1), $\gamma=$ $\left.81.07(1)^{\circ}\right]$. The authors remark that 'the crystal structure ...contains two independent centrosymmetric $\left[\mathrm{Cu}\left(\mathrm{Cl}_{3} \mathrm{C}-\right.\right.$ $\left.\mathrm{COO})_{2}(\mathrm{PhCN})_{2}\right]_{2}$ molecules...quite similar to each other in shape, although there are small differences in their interatomic distances and angles'. The CSD reports that 'a user has pointed out that this structure contains a $C 2$ axis and that the space group should be $C 2 / c^{\prime}$. The $C$-centered cell $(a=23.468$, $\left.b=10.130, c=18.911 \AA, \alpha=89.99, \beta=126.34, \gamma=90.01^{\circ} ; Z=4\right)$ is defined by the vectors [201], [001], [110] of the triclinic cell and the space group is confirmed as $C 2 / c$. Supplementary data are in BCSJ 8514.

\footnotetext{
${ }^{4}$ Transformation from triclinic to centered monoclinic can give an $I$-centered or $C$-centered cell. We have standardized on the $C$-centered cell with the smallest (obtuse) $\beta$ angle.
} 
3.7. (8) FIYGOJ: catena(bis $\left(\left(\mu^{2}\right.\right.$-thiocyanato- $\left.N, S\right)$-2-methylpyridyl)cadmium(II), $\left(\mathrm{C}_{28} \mathrm{H}_{28} \mathrm{Cd}_{2} \mathrm{~N}_{8} \mathrm{~S}_{4}\right)_{n}$ (Taniguchi et al., 1987) ${ }^{5}$

The structure was solved in space group $P \overline{1}[Z=2$ for $n=1$; $a=11.076$ (3), $b=18.478$ (8), $c=9.299$ (3) $\AA$, $\alpha=104.60$ (3), $\left.\beta=114.84(2), \gamma=81.12(2)^{\circ}\right]$. This is a polymeric structure and the authors note that 'there are crystallographically three kinds of cadmium atoms; two of them, $\mathrm{Cd}(1)$ and $\mathrm{Cd}(2)$, are at centers of symmetry $0,0,0$ and $1 / 2,1 / 2,1 / 2$, while the $\operatorname{Cd}(3)$ atom is situated between them'. We comment that the (triclinic) $x, y$ coordinates of $\mathrm{Cd}(3)$ are not significantly different from the suggestive values $x=1 / 4, y=1 / 4$. The triclinic cell can be transformed to C-centered monoclinic $[Z=$ $4 ; a=20.103, b=9.299, c=20.023 \AA, \alpha=90.01, \beta=116.92, \gamma=$ $90.02^{\circ}$; transformation matrix $\left.(201 ; 00 \overline{1} ; 110)\right]$. The r.m.s. deviations from $C 2 / c$ are $0.004,0.003$ and $0.005 \AA$. Cd1 is at Wyckoff position $(d)$ (center of symmetry) and $\mathrm{Cd} 3$ at $(e)$ (twofold axis). Supplementary data in BCSJ 8725.

\section{8. (9) KUSLUF (at $297 \mathrm{~K}$ ) and KUSLUF01 (at $273 \mathrm{~K}$ ): tetrakis(hexylthio)tetrathiafulvalene, $\mathrm{C}_{30} \mathrm{H}_{52} \mathrm{~S}_{8}$ (Nakano et al., 1992)}

The structures at the two temperatures are essentially the same; we consider here only the $297 \mathrm{~K}$ structure. This was solved in space group $P \overline{1}[Z=2 ; a=18.47(1), b=18.516(8)$, $c=5.498$ (4) $\AA$, $\alpha=98.55$ (5), $\beta=89.98$ (6), $\left.\gamma=93.28(4)^{\circ}\right]$; 'there are two independent molecules...in the crystals, each of which has a crystallographic center of inversion'. The triclinic cell can be transformed (matrix 021, 001, 100) to $C$-centered monoclinic $(Z=4 ; a=36.620, b=5.498, c=18.470, \alpha=89.98$, $\left.\beta=93.31, \gamma=90.01^{\circ}\right)$. Relations between coordinates and $B_{\text {eq }}$ values of purportedly independent atoms show that the space group is $C 2 / c$; r.m.s. deviations of the 19 atom pairs from the glide plane in $C 2 / c$ are $0.007 \AA$ in $x$ and $y, 0.013 \AA$ in $z$. The asymmetric unit consists of one half of a centrosymmetric molecule. The large atomic displacement factors of the chain atoms C7, C8 and C9 ( $B_{\text {eq }} \simeq 11.3,18.3$ and 23.6 $\AA^{2}$ ) should be noted. Supplementary data in BCSJ 8725.

\section{9. (10) RICLOE: $\left(\mu^{2}\right.$-2-aminophenylthiolato)-( $\mu^{2}$-hydrido)- decacarbonyltriosmium, $\mathrm{C}_{16} \mathrm{H}_{7} \mathrm{NO}_{10} \mathrm{Os}_{3} \mathrm{~S}$ (Cabeza et al., 1996)}

This compound was reported in space group $P \overline{1}, Z=4$, with (reduced) cell dimensions $a=8.670$ (5), $b=13.61$ (1), $c=$ 19.42 (2) $\AA, \alpha=80.99$ (8), $\beta=89.98$ (6), $\gamma=71.51(8)^{\circ}$. This cell can be converted [matrix $(\overline{1} 20,100,00 \overline{1})$, no origin shift] into a $C$-centered monoclinic cell $(Z=8)$ with dimensions $a=25.815$, $b=8.670, c=19.420 \AA, \alpha=89.99, \beta=116.92, \gamma=89.98^{\circ}$; the two 'independent molecules' in $P \overline{1}$ are related by a $c$ glide in the monoclinic cell within r.m.s. deviations of $\sim 0.008 \AA$.

\footnotetext{
$\overline{\mathbf{5}}$ In footnote 16 to Taniguchi et al. (1987), preliminary data are given for $\mathrm{Cd}(\mathrm{SCN})_{2}$ (pyridine $)_{2}$. The triclinic cell $[a=9.512(2), b=27.357(10), c=$ 9.515 (2) $\AA, \alpha=107.00$ (3), $\beta=112.47$ (2), $\left.\gamma=79.19(3)^{\circ} ; Z=6\right]$ can be transformed to $C$-centered monoclinic $(a=10.575, b=15.818, c=26.206 \AA$ A, $\alpha=$ 89.97, $\beta=95.93, \gamma=90.02^{\circ} ; Z=12$ ). A search of the CSD has not revealed later work on this compound.
}

\subsection{0. (11) TILMEG: [Nd $\left.\left(\eta^{3}-\mathrm{C}_{3} \mathrm{H}_{5}\right)_{3} \cdot\left(\mu-\mathrm{C}_{4} \mathrm{H}_{8} \mathrm{O}_{2}\right)\right]$, $\mathrm{C}_{13} \mathrm{H}_{23} \mathrm{O}_{2} \mathrm{Nd}$ (Taube et al., 1996)}

The structure was reported in a triclinic cell [space group $P \overline{1} ; Z=1 ; a=7.813$ (3), $b=8.114$ (1), $c=13.634$ (3) $\AA, \alpha=$ $74.02(3), \beta=73.08(3), \gamma=61.22(3)^{\circ}$ ]. Fig. 4 of Taube et al. (1996) suggests twofold symmetry. The crystal was lost before completion of their measurements made at $163 \mathrm{~K}$ and these did not extend beyond $\theta=20^{\circ}$, giving a 'measurement to parameter' ratio of $\sim 7$. Thus, the $R$ value of 0.0196 (observed reflections) must be treated with caution. We have transformed the triclinic cell to centered monoclinic, space group $C 2 / \mathrm{c}, Z=4(a=14.223, b=7.813, c=13.813 \AA$, $\alpha=90.26, \beta=$ 111.26, $\left.\gamma=90.00^{\circ}\right)$; transformation matrix (120; $\left.100 ; 0 \overline{1} 1\right)$; shift of origin $\Delta x=1 / 4, \Delta y=1 / 4, \Delta z=0)$. The Nd atom lies on a twofold axis, Wyckoff position $(e)$. With one exception, the coordinates agree with $C 2 / c$ within r.m.s. deviations of $\sim 0.01 \AA$. The exception is the central atom of one allyl group (C12), which in $P \overline{1}$ was represented as disordered between two sites, each with very large displacement parameters. In our revised description we have placed it on the $C_{2}$ axis.

\subsection{1. (12) VEWPOC10: bis(5-chloro-o-(salicylideneamino- methyl)phenolato- $\left.\mathrm{O}, \mathrm{O}^{\prime}, \mathrm{N}\right)$ manganese(IV) tetrahydrofuran solvate, $\mathrm{C}_{28} \mathrm{H}_{20} \mathrm{Cl}_{2} \mathrm{MnN}_{2} \mathrm{O}_{4} \cdot 2 \mathrm{C}_{4} \mathrm{H}_{8} \mathrm{O}$ (Mikuriya et al., 1993)}

The structure was solved in space group $P \overline{1}[Z=2 ; a=$ 12.271 (4), $b=18.196$ (5), $c=8.568$ (2) ̊, $\alpha=103.61$ (2), $\beta=$ $110.42(1), \gamma=96.13(2)^{\circ}$ ]; Fig. 3 of Mikuriya et al. (1993) suggests that the molecule has a twofold axis bisecting angle $\mathrm{O} 2-\mathrm{Mn}-\mathrm{O} 4$. The original triclinic cell can be transformed (matrix 201, 001, $\overline{1} \overline{1} \overline{1}$; origin shift $\Delta x=1 / 4, \Delta y=1 / 4, \Delta z=0$ ) to $C$-centered monoclinic $(Z=4 ; a=23.000, b=8.568, c=18.991$, $\left.\alpha=90.02, \beta=114.36, \gamma=89.99^{\circ}\right)$. The coordinates agree with $C 2 / c$ within r.m.s. deviations of $\sim 0.002 \AA$, not only for the molecule of the complex itself ( $B \simeq 3.2-7.3 \AA^{2}$ ), but also for the THF solvent of crystallization $\left(B_{\text {eq }} \simeq 11-18 \AA^{2}\right)$. The twofold symmetry of the molecule is confirmed, with $\mathrm{Mn}$ at Wyckoff position (e), symmetry 2. Supplementary data in BCSJ 66007.

\subsection{2. (13) WABKOZ: $\operatorname{Rh}\left(\mathrm{C}_{6} \mathrm{H}_{5}\right) \mathrm{Cl}_{2}\left(\mathrm{PPh}_{3}\right)_{2}$ (Fawcett et al., 1992)}

This structure was solved in space group $P \overline{1}[Z=2 ; a=$ 9.532 (28), $b=9.523$ (24), $c=21.800$ (19) $\AA$, $\alpha=112.9$ (1), $\beta=$ $\left.85.9(1), \gamma=94.0(1)^{\circ}\right]$. The reduced cell has dimensions $a=$ 9.532, $b=9.523, c=20.109 \AA, \alpha=92.55, \beta=92.96, \gamma=94.0^{\circ}$. In view of the large uncertainties in cell dimensions, this reduced cell is satisfactorily close to the aac $\alpha \alpha \gamma$ form. Fig. 1 of Fawcett et al. (1992) suggests that the molecule has a twofold axis. The triclinic cell can be transformed to a $C$-centered monoclinic cell $(Z=4 ; a=12.99, b=13.93, c=20.11 \AA$, $\alpha=90.3, \beta=94.0$, $\left.\gamma=90.1^{\circ}\right)$; transformation matrix $(\overline{1} \overline{1} 0 ; 1 \overline{1} 0 ; 011)$, origin shift $1 /$ $4,1 / 4,0)$; the deviations of $\alpha$ and $\gamma$ from $90^{\circ}$ may presumably be disregarded. Relations between coordinates agree with $C 2$ / $c$ within $0.003 \AA$, with the $C_{2}$ axis passing through the Rh atom and the coordinated phenyl group. 
3.13. (14) YATZOI10: $\left[\mathrm{Ni}_{4}(\mathrm{~L})_{2}(\mathrm{pz})_{2}\left(\mathrm{CH}_{3} \mathrm{OH}\right)\right]$, where $\mathrm{H} 3 \mathrm{~L}$ is 2,6-bis(salicylideneaminomethyl)-4-methylphenol and $\mathrm{Hpz}$ is pyrazole, $\mathrm{C}_{53} \mathrm{H}_{48} \mathrm{~N}_{8} \mathrm{O}_{7} \mathrm{Ni}_{4}$ (Mikuriya et al., 1996)

The structure was solved in $P \overline{1}[a=13.017(3), b=$ 13.018 (4), $c=17.782$ (5) $\AA$, $\alpha=96.00$ (2), $\beta=107.26$ (2), $\gamma=$ $116.82(2)^{\circ} ; Z=2$ ]. This is the Niggli reduced cell, and the equality of $a$ and $b$ might have given rise to suspicions about higher symmetry. The triclinic cell can be transformed [(11)

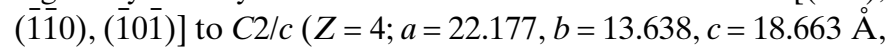
$\left.\alpha=89.98, \beta=119.12, \gamma=90.00^{\circ}\right)$. The r.m.s. deviations from $C 2 / c$ are $0.007 \AA$ in $x$ and $y, 0.006 \AA$ in $z$. The molecule, which has $C_{1}$ symmetry in the original, triclinic description is located about a twofold axis in the revised monoclinic description; the methanol solvate $\mathrm{C} 53-\mathrm{O} 7$ lies on a twofold axis (see Fig. 4 of Mikuriya et al., 1996). The atoms C10-C15 of the peripheral benzene ring, and the methanol methyl, have large ADPs and the associated geometry remains poorly defined even after revision of the space group. Supplementary data in BCSJ 69005.

\subsection{4. (15) TUMLES: $\mathrm{C}_{27} \mathrm{H}_{24} \mathrm{~N}_{3} \mathrm{O}_{2}$ Ir.2 $\mathrm{H}_{2} \mathrm{O}$ (Urban et al., 1996)}

This structure was reported in a monoclinic cell with dimensions $a=10.322$ (3), $b=17.864$ (5), $c=13.005$ (6) $\AA, \beta=$ $90.24(3)^{\circ}, Z=4$, space group $P 2{ }_{1}$. Upon shifting the origin by 0.3446 in $y$ and 0.25 in $z$, the two molecules in the asymmetric unit can be averaged according to space group $P 2_{1} 2_{1} 2_{1}$ within r.m.s. deviations of less than $0.03 \AA$. In view of this agreement, we have no doubt that the additional reflection conditions ' $h 00,00 l$ absent for $h, l$ odd' were overlooked, or that the deviation of $\beta$ from $90^{\circ}$ is due to measurement error. The change in space group does not affect the chirality of the structure, which is imposed by the presence of L-proline. The two water molecules O5 and O7 are only $1.36 \AA$ apart, in either space group. Their environments and their $U_{\text {eq }}$ values strongly suggest that they represent a molecule of methanol, which was used as a solvent during the synthesis, and hence that the structure should be described as a methanolate rather than a dihydrate.

\subsection{5. (16) CECMAY10: complex of hexakis(2,3,6-tri-O- methyl)-a-cyclodextrin with $(S)$-mandelic acid, $\mathrm{PhCH}(\mathrm{OH})$ - $\mathrm{COOH}, \mathrm{C}_{54} \mathrm{H}_{96} \mathrm{O}_{30} \cdot \mathrm{C}_{8} \mathrm{H}_{8} \mathrm{O}_{3} \cdot 3 \mathrm{H}_{2} \mathrm{O}$ (Harata et al., 1987)}

This complex was reported as monoclinic $\left[P 2_{1}, Z=2, a=\right.$ $13.123(2), b=23.187$ (4), $\left.c=13.113(2) \AA, \beta=107.19(1)^{\circ}\right]$. The near equality of $a$ and $c$ indicates that (101) and (101) are approximately perpendicular and hence that a centered orthorhombic lattice should be considered. The transformation matrix $(101 ; 10 \overline{1} ; 010)$ leads to a $C$-centered orthorhombic cell $(Z=4, a=15.571, b=21.116, c=23.187 \AA$, $\alpha=90.00, \beta=$ $\left.90.00, \gamma=89.95^{\circ}\right)$. The origin shift is $\Delta x=-0.250$ (2), $\Delta y=$ -0.000 (2), $\Delta z=0.249$ (1), i.e. $1 / 4,0,0.249$ (1) (the origin shift in $z$ is not exactly $1 / 4$ as the original $b$ axis is polar). The two halves of the cyclodextrin molecules (C1-O15; C28-O30; CSD numbering) are related by a twofold axis running along $y$ at $(0$, $y,-1 / 4)$. This establishes the orthorhombic space group as
$C 222_{1}$ and the origin shift brings the arrangement into conformation with the standard setting. Harata et al. (1987) remarked that 'the methyl-alpha-CDx molecule has a pseudo twofold symmetry'. The $B_{\text {eq }}$ values of the atoms of the $\mathrm{C}_{54} \mathrm{H}_{96} \mathrm{O}_{30}$ molecule range from 4.76 to $17.35 \AA^{2}$, while those of the atoms of $S$-mandelic acid (disordered across the twofold axis) and water range from 14.37 to $33.09 \AA^{2}$. Despite this, most of the atoms of mandelic acid and the water $\mathrm{O}$ atoms can be identified. Supplementary data are in BCSJ 8719.

\subsection{6. (17) JIGREW: O-methyl-neopyrrolomycin, $\mathrm{C}_{11} \mathrm{H}_{6} \mathrm{Cl}_{5} \mathrm{NO}$ (Nogami et al., 1990)}

The structure was solved in space group $P 2_{1}[Z=4 ; a=$ 8.564 (5), $b=23.838$ (10), $c=7.246$ (5) $\left.\AA, \beta=115.09(5)^{\circ}\right]$, the absolute configuration being determined. Analogous atoms in the two purportedly independent molecules $(A$ and $B$ ) have $x_{A}=x_{B}, y_{A}+y_{B} \simeq 0.258$. The monoclinic cell can be transformed to orthorhombic, the new cell $(Z=8 ; a=7.246, b=$ 15.512, $c=23.838 \AA, \alpha=90.00, \beta=90.00, \gamma=90.06^{\circ}$ ) being defined by the vectors [001], [201], [010] of the monoclinic cell. The two molecules are now related by a twofold axis running along $y$; this twofold axis is apparent in Fig. 3 of Nogami et al. (1990), running diagonally upwards from right to left in the figure. The orthorhombic space group is thus established as $C 222_{1}$ (No. 20), and an origin shift in $C 222_{1}$ of $\Delta x=1 / 4, \Delta z=$ 0.1213 brings the arrangement into agreement with the standard setting. The r.m.s. deviations from $C 222_{1}$ are $0.016,0.006$ and $0.005 \AA$. The large deviation in $x$ is due primarily to the $\mathrm{Cl} 2-\mathrm{Cl} 7$ match. Bond lengths and angles suggest that the original $\left(P 2_{1}\right) z$ coordinate of $\mathrm{Cl} 7$ should be 0.35767 rather than 0.35567. The inter-ring torsion angles -78.1 (1.2) and $-82.4(1.1)^{\circ}$, given as 'similar' $(\Delta / \sigma=2.64)$, are in fact equal $\left(\right.$ at $\left.-80.3^{\circ}\right)$.

3.17. (18) VOGLUY: (hydrogen-tris(3,5-dimethylpyrazolyl)borate- $\left.N, N^{\prime}, N^{\prime \prime}\right)$ - $\left(\mu^{2}\right.$-carbonato- $\left.O, O, O^{\prime}, O^{\prime \prime}\right)$ dicopper(II), $\mathrm{C}_{31} \mathrm{H}_{44} \mathrm{~B}_{2} \mathrm{Cu}_{2} \mathrm{~N}_{12} \mathrm{O}_{3}$ (Kitajima et al., 1991)

The structure was solved in space group $P 2_{1}[Z=2 ; a=$ 8.068 (1), $b=1.008$ (5), $c=8.064$ (1) $\AA, \beta=113.59$ (1) $)^{\circ}$. As in the example of CECMAY10, the equality of $a$ and $c$ suggests higher symmetry; furthermore, careful inspection of Fig. 5 of Kitajima et al. (1991) suggests that the molecule might have a mirror plane, passing through the $\mathrm{Cu}$ atoms. The monoclinic cell can be transformed to orthorhombic $(Z=4 ; a=13.498, b=$ 8.834, $\left.c=31.008 \AA, \alpha=90.00, \beta=90.00, \gamma=90.03^{\circ}\right)$, space group $C m c 2_{1}$ (No. 36), indicating a change from a chiral to an achiral structure. The vectors (in the monoclinic cell) defining the orthorhombic cell are [101], [101], [010]. Supplementary material is available from J. Am. Chem. Soc.

3.18. (19) WIFFOG: bis-[( $\eta^{5}$-pentamethylcyclopentadienyl)tetrahydroborato]uranium(IV), $\left[\mathrm{U}\left(\mathrm{C}_{5} \mathrm{Me}_{5}\right)_{2} \cdot\left(\mathrm{BH}_{4}\right)_{2}\right](\mathrm{Gradoz}$ et al., 1994)

The structure was reported in space group $C m, Z=2[a=$ 8.187 (6), $b=15.172$ (8), $c=9.717$ (4) $\left.\AA, \beta=114.82(5)^{\circ}\right]$. The monoclinic cell can be transformed to F-centered ortho- 
rhombic $(a=17.639, b=15.172, c=8.187 \AA, \alpha=90.00, \beta=$ $90.09, \gamma=90.00^{\circ}, Z=4$; the new cell is defined by the vectors [102], [010], [100] of the monoclinic cell). The coordinate relations $x, y, z ;-x, y, z$ show that the space group is Fmm 2 (No. 42). The $\mathrm{U}$ atom is at Wyckoff position (a), with site symmetry $m m$, and the B at $(c)$, with site symmetry $m$.

3.19. (20) and (21), AZPADO: 1,3,5-triaza-7-phosphaadamantane-7-oxide, $\mathrm{C}_{6} \mathrm{H}_{12} \mathrm{~N}_{3} \mathrm{OP}$, and AZPADS, 1,3,5triaza-7-phospha-adamantane-7-sulfide, $\mathrm{C}_{6} \mathrm{H}_{12} \mathrm{~N}_{3} \mathrm{SP}$; both at $153 \mathrm{~K}$ (Jogun et al., 1978)

These two compounds were reported in space group $\mathrm{Cm}$ $[Z=2$; AZAPDO, $a=7.220$ (7), $b=9.279$ (8), $c=5.897$ (4) $\AA$, $\beta=113.24(5)^{\circ}$; AZPADS, $a=7.704$ (1), $b=9.326(2), c=$ 6.048 (1) $\left.\AA, \beta=107.30(1)^{\circ}\right]$. It was noted that 'in the crystal, molecules of AZPADO and AZPADS display exact (crystallographic) mirror symmetry..., both also display a good approximation to $C_{3 v}$ symmetry'. The vibration spectra of both crystals (and also in solution) were consistent with $C_{3 v}$ symmetry. The monoclinic cell can be transformed to rhombohedral $R 3 m$ [transformation matrix from monoclinic to rhombohedral axes $(0.5,-0.5,0) ;(0.5,0.5,0) ; 0,0,1)]$ to give cells with averaged parameters $5.885 \AA$, $104.09^{\circ}$; $6.048 \AA$, $100.90^{\circ}(Z=1)$. The r.m.s. coordinate fits to $R 3 m$ are 0.004 and $0.003 \AA$, respectively. The molecules have exact $C_{3 v}$ symmetry.

\subsection{0. (22) No REFCODE as inorganic, $\left.\left[\mathrm{LiNa} \mathrm{NaO}_{3}\right)_{2} \cdot 6 \mathrm{H}_{2} \mathrm{O}\right]$ (Makitova et al., 1989)}

This compound was reported in space group $B b[a=$ 15.132 (5), $b=14.482$ (5), $c=8.732$ (5) $\AA, \gamma=45.83(3)^{\circ}, Z=4$; $c$ axis unique]. The space group was chosen on the basis of more satisfactory refinement in $B b$ than in $B 2 / b$. Except for the unusual value for the angle $\gamma$, these cell dimensions provide no hint of higher symmetry. However, the reduced cell $\left(a=8.732, b=8.735, c=11.547, \alpha=67.77, \beta=67.78, \gamma=60.01^{\circ}\right)$ is suspicious; indeed, it falls into category 9 (rhombohedral) of Table 9.3.1, p. 742, of International Tables for X-ray Crystallography, Volume A (1983). The (obverse) hexagonal cell, $a=$ $8.735, b=8.732, c=31.163 \AA, \alpha=90.00, \beta=90.01, \gamma=119.99^{\circ}$, $Z=6$ is derived from the vectors $\left[\frac{1}{2} 0 \frac{1}{2}\right],[00 \overline{1}],[2 \overline{3} 0]$ of the monoclinic cell. The revised space group is $R 3 \mathrm{c}$ and the two Mo atoms and $\mathrm{Li}, \mathrm{O} 1$ and $\mathrm{O} 8$ lie on $C_{3}$ axes. The r.m.s. deviations of the atoms from $R 3 c$ are somewhat larger than usual - up to $\sim 0.05 \AA$ for the $\mathrm{O}$ atoms, perhaps because absorption was not taken into account ( $\mathrm{Cu}$ radiation).

3.21. (23) NEGXOM: dipotassium trans-(dichloro-bis(glutarimidato)palladium(II)) hydrate, trans-

$\mathrm{K}_{2}\left[\mathrm{Pd}\left(\mathrm{C}_{5} \mathrm{H}_{6} \mathrm{NO}_{2}\right)_{2} \mathrm{Cl}_{2}\right] \cdot 4.5 \mathrm{H}_{2} \mathrm{O}$ (Michalska et al., 1996)

The structure was solved in space group $P 2_{1} / c[Z=4 ; a=$ 17.438 (3), $b=16.225$ (3), $c=7.932$ (2) $\AA, \beta=117.03$ (3) $\left.{ }^{\circ}\right]$ with two independent $\mathrm{Pd}$ anions lying on different centers of symmetry. The vectors [101], [010], [001] transform this monoclinic cell to orthorhombic $(a=15.533, b=16.225, c=$ $7.932 \AA, \alpha=90.00, \beta=89.97, \gamma=90.00^{\circ}$ ), r.m.s. deviations from space group Pccn (No. 56) are $\sim 0.003 \AA$ in all three coordi- nates. In this description the Pd complex again lies on an inversion center; the two $\mathrm{K}^{+}$cations with their coordinated $\mathrm{O}$ atoms and water molecules are located around a twofold axis. Surprisingly, the atoms of the six-membered ring are coplanar within $0.1 \AA$ and the aliphatic bonds $\mathrm{C} 2-\mathrm{C} 3$ and $\mathrm{C} 3-\mathrm{C} 4$ are very short, at $1.40 \AA$. Atom $\mathrm{C} 3$ and its symmetry-equivalent C8 show large displacement parameters with $U_{\text {eq }} \simeq 0.11 \AA^{2}$, presumably representing disordered puckering of the ring. The three water $\mathrm{O}$ atoms $(\mathrm{O} 5, \mathrm{O} 7, \mathrm{O} 9)$ have $U_{\text {eq }}$ values $(0.17$, 0.11 and $0.22 \AA^{2}$ ) approximately twice as large as those of most other atoms in the structure. The O9..O 5 distance between water molecules is unrealistically short at $2.42 \AA$, probably because of disorder of the water molecules.

\subsection{2. (24) YIVWOP: $\mu$-hydroxycyclooctadien $(1,5)$ rhodium(I) dimer, $[(\mu-\mathrm{OH}) \mathrm{Rh}(\mathrm{COD}-1,5)]_{2},\left[\mathrm{C}_{16} \mathrm{H}_{26} \mathrm{O}_{2} \mathrm{Rh}_{2}\right]$, at $173 \mathrm{~K}$ (Selent \& Ramm, 1995)}

This compound was solved in space group $C 2 / c, Z=16$ units of $\left[\mathrm{C}_{16} \mathrm{H}_{26} \mathrm{O}_{2} \mathrm{Rh}_{2}\right]$ and not 8 , as printed in their Table $1[a=$ 31.687 (3), $b=12.216$ (2), $c=22.414$ (2) $\left.\AA, \beta=135.006(7)^{\circ}\right]$. 'In the solid state, the asymmetric unit contains two molecules which are bonded via one intermolecular hydrogen bond. Two such dimers interact by two additional hydrogen bonds, giving a tetramer.' The lattice vectors [001], [101], [010] transform the monoclinic cell to body-centered tetragonal $(Z=16$; $a=$ 22.414, $b=22.404, c=12.216, \alpha=90.00, \beta=90.00, \gamma=89.99)$; after similar transformation followed by translation of the origin to the center at $1 / 4,1 / 4,0$, the coordinates are compatible with space group $I 4_{1} / a$ (No. 88). The $\left[\mathrm{C}_{16} \mathrm{H}_{26} \mathrm{O}_{2} \mathrm{Rh}_{2}\right]$ moieties are linked into tetramers with symmetry $\overline{4}$ by hydrogen bonding between $\mathrm{O} 2$ atoms $(d=2.89 \AA)$.

3.23. (25) TONWUO: catena-(tetrakis $\left(\mu_{2}-1,4\right.$-diazoniabicyclo(2.2.2)octane-1,4-dipropianato)dizinc(II) tetraperchlorate, $\left(\mathrm{C}_{48} \mathrm{H}_{80} \mathrm{~N}_{8} \mathrm{O}_{16} \mathrm{Zn}_{2}\right)^{4+} .4 \mathrm{ClO}_{4}{ }^{-}$(Wei et al., 1996)

This compound was reported in space group $C 2 / c, Z=4, a=$ 24.970 (1), $b=19.252$ (1), $c=15.913$ (1) $\AA, \beta=129.46$ (1) ${ }^{\circ}$. The lattice vectors [101], [010], [001] transform the monoclinic cell to body-centered tetragonal $(Z=8, a=19.279, b=19.252, c=$ $15.913 \AA, \alpha=90.00, \beta=89.87, \gamma=90.00^{\circ}$; the revised space group is $I 4_{1} /$ acd (No. 142). The $\mathrm{Zn}$ atom lies on Wyckoff position $8(b)$ (symmetry 222 ) and the $\mathrm{Cl}$ at Wyckoff position $16(f)$ (symmetry 2). The perchlorate anions show twofold orientational disorder. Revision of the space group reduces the number of atoms to be refined by a factor of approximately 4 .

\subsection{4. (26) PYRDNO10: pyridine $\mathrm{N}$-oxide, $\mathrm{C}_{5} \mathrm{H}_{5} \mathrm{NO}$ (Ülkü et al., 1971)}

The structure of (very hygroscopic) pyridine $N$-oxide was reported in the orthorhombic space group $C 222_{1}[a=$ 8.230 (7), $b=8.221$ (7), $c=13.747$ (8) $\AA, Z=8] .305 F_{\text {obs }}$ values, measured photometrically from integrated Weissenberg photographs $(\mathrm{Cu} K \alpha)$, were included in the paper; plotting $F(k h l)$ against $F(h k l)$ for 89 pairs gave a straight line with $F(k h l)=0.9117 F(h k l)+0.8757, R^{2}=0.9620 ; R($ merge $)=0.056$. 
The $a$ and $b$ axes are not significantly different and there are obvious relations between the coordinates of atoms in the two purportedly independent molecules in the asymmetric unit. Reduction of the cell (BLAF, CSD) gives a primitive tetragonal cell with $a=5.816, b=5.816, c=13.747 \AA$ А $\alpha=90.00, \beta=$ $90.00, \gamma=90.06^{\circ}, Z=4$. Thus, there is firm evidence for a tetragonal cell defined by the lattice points $\frac{1}{2},-\frac{1}{2}, 0 ; \frac{1}{2}, \frac{1}{2}, 0 ; 001$ of the orthorhombic cell. The space group was determined by comparing the packing diagrams in the orthorhombic and tetragonal cells. The space group $P 4_{1} 2_{1} 2$ has reflection conditions $001, l=4 n ; h 00, h=2 n$; the only $00 l$ reflections given in the $F$-list were 0012 and $0016,{ }^{6}$ and the only $h 00$ reflections were 200, 400 and 600 . Thus, the reflection list is compatible with $P 4_{1} 2_{1}$ 2. Least-squares refinement (on $F^{2}$ ) of 45 parameters using 261 independent (tetragonal) reflections gave $R_{1}=0.0633, w R_{2}=0.1724$ for all data. The bond lengths from the refinement are $\mathrm{N}-\mathrm{O} 1.330(9), \mathrm{C}-\mathrm{N} 1.348$ (6), $\mathrm{C}-\mathrm{C}$ $1.371(8), 1.374(7) \AA$, and the bond angles in the ring $\mathrm{C} 2-$ $\mathrm{N}-\mathrm{C}_{2} * 121.0(7), \quad \mathrm{N}-\mathrm{C} 2-\mathrm{C} 3 \quad 119.7(5), \quad \mathrm{C} 2-\mathrm{C} 3-\mathrm{C} 4$ 120.9 (6), $\mathrm{C} 4-\mathrm{C} 3-\mathrm{C} 4 * 117.9(9)^{\circ}$; the molecule has a twofold axis. The only other report we have found is a study of $\mathrm{C}-$ $\mathrm{H} \cdots \mathrm{O}$ bonding in pyridine $N$-oxide (Bodige et al., 1999); the 'orthorhombic' symmetry was not questioned.

\subsection{5. (27) ROBJEX: $2,2^{\prime}$-(methylenedioxy)-bis(phenylisocya-} nide), $\mathrm{C}_{15} \mathrm{H}_{10} \mathrm{~N}_{2} \mathrm{O}_{2}$ (Hahn et al., 1996)

The structure was reported in the tetragonal space group $P 4_{1}(Z=4 ; a=9.591, c=13.431 \AA)$; Hahn et al. (1996) remarked that the space group was 'assumed (our italics) to be $P 4_{1}$ (No. 76) ...Solution and refinement of the structure... confirmed this choice'. Also 'the [choice of the] correct crystallographic enantiomer in the polar space group...[was made] by selection of the set of coordinates giving the better residuals'. Intensity data were collected using Mo $K \alpha$ radiation and it seems unlikely that the authors could have ruled out the opposite space group $P 4_{3}$. We have revised the space group to $P 4{ }_{1} 2{ }_{1}$ (No. 92), the origin was shifted by $\Delta x=0.0, \Delta y=0.5$, $\Delta z=-0.0429$. The r.m.s. deviation of the coordinates from the higher symmetry is $\sim 0.012 \AA$. The molecule has a crystallographic twofold axis in the revised space group ( $c f$. Fig. 2 of Hahn et al., 1996). This is an example where investigators, after arriving at an incorrect Laue symmetry, failed to notice the additional reflection condition $h 00(0 k 0)$ absent for $h(k)$ odd.

\subsection{6. (28) JUNNAH: bis[cis-cyclohexane triaminezinc bis(trifluoromethylsulfonate), $\left[\left(\mathrm{C}_{6} \mathrm{H}_{9}\left(\mathrm{NH}_{2}\right)_{3}\right] \mathrm{Zn}\left(\mathrm{CF}_{3} \mathrm{SO}_{3}\right)_{2}\right.$, $\mathrm{C}_{14} \mathrm{H}_{30} \mathrm{~F}_{6} \mathrm{~N}_{6} \mathrm{O}_{6} \mathrm{~S}_{2} \mathrm{Zn}$ (Brand \& Vahrenkamp (1992a,b)}

This compound was reported in $R 3, Z=12$ [ $a=19.234$ (3), $c=23.582(5) \AA]$. The hexagonal cell can be transformed (matrix $\frac{2}{3}, \frac{1}{3}, \frac{1}{3}, \frac{1}{3}, \frac{1}{3}, \frac{1}{3},-\frac{1}{3},-\frac{2}{3}, \frac{1}{3}$ ) to primitive cubic, $Z=4, a=$ $13.605 \AA, \alpha=89.96^{\circ}$, space group $P 2_{1} 3$ (No. 198). The Zn, S1, S2, C17, C18 atoms are at Wyckoff (a) sites (symmetry 3 ). In the $R 3$ structure, there are two crystallographically distinct cations and four distinct anions; one of the cations and two of

\footnotetext{
${ }^{6}$ The 'extremely intense' 004 was observed, but not included in the $F$-list as it 'appeared to be suffering badly from extinction'.
}

the anions lie on $C_{3}$ axes and the remaining are in general positions. In the revised structure all the ions lie on $C_{3}$ axes. Both space groups are chiral. Although the $\mathrm{S}-\mathrm{O}$ distances are rather uniform at $1.41-1.45 \AA$, there are appreciable deviations in $\mathrm{S}-\mathrm{C}\left(1.82-2.22 \AA\right.$ in $R 3,1.89-2.16 \AA$ in $\left.P 2{ }_{1} 3\right)$ and $\mathrm{C}-$ F distances (1.16-1.31 $\AA$; 1.20-1.30 ̊), which were ascribed to disorder of the anions.

\subsection{7. (29) TAZPAD: 1,3,5-triaza-7-phospha-adamantane (monophospha-urotropine), $\mathrm{C}_{6} \mathrm{H}_{12} \mathrm{~N}_{3} \mathrm{P}$ (Fluck et al., 1977)}

This structure was reported in the chiral space group $R 3$ [hexagonal axes 9.618 (3), 7.004 (3) $\AA$; $Z=3$, not ' 1 ' as printed). It is properly described in achiral $R 3 m$ and is isostructural with AZPADO and AZPADS, which were originally described in Cm (Jogun et al., 1978; see above).

\subsection{8. (30) POJKAA: trans- $\left[\mathrm{Pt}\left(\mathrm{CF}_{3}\right)\left\{\mathrm{N}=\mathrm{C}(\mathrm{Ph}) \mathrm{OCH}_{2} \mathrm{CH}_{2} \mathrm{CH}_{2}\right\}\left(\mathrm{PPh}_{3}\right)_{2}\right] \mathrm{BF}_{4}$, $\left[\mathrm{PtC}_{45.8} \mathrm{H}_{41} \mathrm{~F}_{6.4} \mathrm{NOBP}_{2}\right] \mathrm{Cl}_{0.2}$ (Michelin et al., 1994)}

This compound was reported in space group $P \overline{3}$ (No. 147) with $a=22.590$ (4), $c=15.970$ (3) $\AA, Z=6$. An initial structure solution in $P 6_{3} / m$ (No. 176) was rejected because it could not be refined below $R=0.08$, the reflection condition ' $000 \mathrm{l}$ absent for $l \neq 2 n$ ' being considered 'accidental'. However, the coordinates reported are entirely compatible with $P 6_{3} / m$. The cation is in Wyckoff position 6(h), symmetry $m$. Although it was stated that 'the $\mathrm{BF}_{4}$ anions were located [in] on the crystallographic threefold axis with three distinct positions...', coordinates of this group were not reported. It was also remarked that 'a disordered methanol of crystallization is also present in the structure', although the formula used for calculating analytical figures included $1 / 2 \mathrm{CH}_{2} \mathrm{Cl}_{2}$ rather than methanol; coordinates for the solvent (whatever it is) were not given. The r.m.s. deviations of the coordinates and $U^{i j}$, s from $P 6_{3} / m$ symmetry are almost exactly the same as the s.u.'s reported for these parameters $(\sim 0.015 \AA$ for light-atom coordinates). Thus, the reported structure has $\mathrm{Pb}_{3} / \mathrm{m}$ symmetry within experimental error. The failure to achieve satisfactory refinement in $P 6_{3} / m$ was possibly due to erroneous assignment of site multiplicities when transforming between space groups.

\subsection{9. (31) FABTAD10: carbon tetrachloride-thiourea (1/3) adduct at $170 \mathrm{~K}, \mathrm{CCl}_{4} \cdot 3\left[\mathrm{SC}\left(\mathrm{NH}_{2}\right) 2\right]$ (Fait et al., 1991)}

The structure of this thiourea channel inclusion complex was reported in space group $R \overline{3}\left[Z=6,{ }^{7} a=15.539\right.$ (4), $c=$ 12.529 (9) $\AA$ ], although all other thiourea channel inclusion complexes have been found, above the rhombohedral-tomonoclinic phase transformation, in space group $R \overline{3} c$. Inspection of the coordinates shows that both the host thiourea molecule and the guest $\mathrm{CCl}_{4}$ molecule (which is disordered) lie on $C_{2}$ axes of $R \overline{3} c$ within r.m.s. deviations of less than $0.02 \AA$.

\footnotetext{
${ }^{7}$ Misprinted as $Z=18$ in the paper.
} 


\subsection{0. (32) FISMUP: adamantane-1,3-diol, $\mathrm{C}_{10} \mathrm{H}_{16} \mathrm{O}_{2}$ (Prozorovskii et al., 1987)}

This structure was described in the polar space group $C m c 2_{1}$ $\left[a=20.584(5), b=11.886(3), c=10.939\right.$ (3) $\left.\AA, Z=12^{8}\right]$. The ratio $3 b / a$ is 1.732 and accordingly the cell can be recast as hexagonal (transformation: $\frac{1}{2}, \frac{1}{2}, 0 ; 0,1,0 ; 0,0,1 ; a=11.885, c=$ $10.939 \AA, Z=6$ ). After the origin is shifted by 0.5 in $y$ and -0.525 in $z$, coordinates can be matched to space group $P 6_{3} / \mathrm{mcm}$ (No. 193), within r.m.s. deviations of $\sim 0.05 \AA$. The molecule now has $\mathrm{mm}$ symmetry and the structure is nonpolar. Since the change in structure involves adding a center of inversion, changes in molecular dimensions are important. For example, whereas the $\mathrm{C}-\mathrm{C}$ distances ranged from 1.39 to $1.67 \AA$ in the $C m c 2_{1}$ description, in the revised structure they lie between 1.53 and $1.55 \AA$. The molecules are hydrogen bonded in groups of six, with the hydroxyl $\mathrm{O}$ atoms arranged in a puckered hexagon, the torsion angle around the ring of $-40^{\circ}$ showing that the hexagon has a chair form; $[d(\mathrm{O} \cdots \mathrm{O})=$ $2.77 \AA$ ]. Disordered positions seem likely for the $\mathrm{H}$ atoms of the hydroxyl groups as these were not located in the structure analysis. The 1,3-adamantanediol molecules are alternately canted above and below the mean plane of the hydroxyl hexagon. The hexagons of adamantane-1,3-diol molecules are arranged in columns along [0001] and these columns are themselves packed in a hexagonal fashion. There are only van der Waals interactions between adjacent columns.

\subsection{Additional example: Not listed in CSD: diaquabis(iso- butyrato)dioxouranium(VI), $\mathrm{UO}_{2}\left(\left(\mathrm{CH}_{3}\right)_{2} \mathrm{CHCOO}\right)_{2} \cdot 2 \mathrm{H}_{2} \mathrm{O}$ (Yuranov \& Dunaeva, 1989)}

We note one additional compound which may belong in this section. This structure was reported as monoclinic, $C 2 / c, Z=4$; $a=16.531$ (2), $b=7.676(1), c=10.822$ (2), $90.49(2)^{\circ}$. It is suspiciously close to orthorhombic, space group $\mathrm{Cccm}$. The coordinates in Table 1 of Yuranov \& Dunaeva (1989) are compatible with $\mathrm{Cccm}$ after:

(i) shifting the atoms $\mathrm{O} 1, \mathrm{C} 1$ and $\mathrm{C} 2$ by insignificant amounts $-0.03 \AA$ or less - onto the mirror plane at $z=0.5$, and analogously relating $\mathrm{O} 2, \mathrm{O} 3$ across this mirror plane;

(ii) moving the water molecule $\mathrm{O} 4$ by $\sim 0.15 \AA$ ( 7 sigma) onto a twofold axis at $x=y=0.25$;

(iii) symmetrizing the methyl carbon atoms $\mathrm{C} 3$ and $\mathrm{C} 4$ across the mirror plane at $z=0.5$, requiring shifts of $\sim 0.1 \AA$ (2.5 sigma).

In view of the facts that these shifts appear to be statistically significant, that the deviation of the $\beta$ angle from $90^{\circ}$ is relatively large and that $C \mathrm{ccm}$ would require the additional reflection conditions of $0 \mathrm{kl}$ absent for $l$ odd, we do not include this example in our list (or give revised coordinates). We note, though, that the crystal was quite large $(0.3 \times 0.3 \times 0.1 \mathrm{~mm}$; Mo radiation) and that absorption or misalignment problems might have been responsible for the apparent deviations from Cccm.

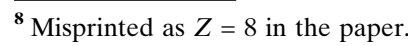

\section{Category B: add a center of symmetry}

4.1. (33) YOJBUU: bis(ethylenediammonium) hexachlororuthenium chloride monohydrate, $2\left(\mathrm{C}_{2} \mathrm{H}_{10} \mathrm{~N}_{2}{ }^{2+}\right)\left(\mathrm{Cl}_{6} \mathrm{Ru}_{3}\right)^{3-} \mathrm{Cl}^{-} \cdot \mathrm{H}_{2} \mathrm{O}$ (Balakaeva et al., 1994)

This structure was reported in space group $P 2_{1}, Z=2[a=$ 10.393 (2), $b=10.031$ (2), $c=8.089$ (1) $\AA, \beta=90.66^{\circ}$ (angle not reported in the original paper but supplied by the CSD)]. Shifting all the atoms by $\Delta y=0.10$ places the Ru atom and six others on a mirror plane, the space group becoming $P 2_{1} / \mathrm{m}$. The octahedral $\left(\mathrm{RuCl}_{6}\right)^{3-}$ anions are at Wyckoff $(e)$ positions, with mirror symmetry; the chloride anion $(\mathrm{Cl} 7)$ and the water molecule also lie on a mirror plane. The two independent ethylenediammonium dications lie on separate centers of symmetry [Wyckoff positions $(a)$ and $(c)$ ]; hence, the $\mathrm{N}-\mathrm{C}-$ $\mathrm{C}-\mathrm{N}$ groupings are planar. The r.m.s. deviations from $P 2_{1} / \mathrm{m}$ are relatively small, $\sim 0.03 \AA$. We further note that, except for a mismatch of $\sim 1 \AA$ in the relative positions of the chloride ion and the water molecule, the structure can be described as approximately $C$-centered (space group $C 2 / m$ ).

\section{2. (34) HEFSIU: catena( $\mu^{3}$-aqua)-( $\mu^{2}$-aqua)tetrakis $\left(\mu^{4}-4-\right.$ hydroxy-3-nitrobenzenesulfonato)tetrasodium), $\mathrm{Na}_{4}\left[\mathrm{HO}\left(\mathrm{O}_{2} \mathrm{~N}\right) \mathrm{C}_{6} \mathrm{H}_{3} \mathrm{SO}_{3}\right]_{4} \cdot 2 \mathrm{H}_{2} \mathrm{O}$ (Shubnell et al., 1994)}

This compound was reported in space group $P c$ with cell dimensions $a=8.293$ (3), $b=16.580$ (2), $c=13.465$ (2) $\AA, \beta=$ $90.29(2)^{\circ}, Z=2$. The authors note that 'a statistical comparison of the intensities of symmetry-related reflections satisfactorily confirmed the monoclinic symmetry'. Thus, here the deviation of $0.3^{\circ}$ in $\beta$ from $90^{\circ}$ is a real effect. The space group $P c$ (suggested by the systematic absences) was stated to have been confirmed by 'successful solution and refinement of the structure. Attempts to model the structure in the centrosymmetric space group $P 2 / c$ (which carries the same absence condition) were unsuccessful'. However, after shifting the origin by $\Delta x=-0.260, \Delta z=-0.629$, the atom coordinates can be averaged according to space group $P 2 / c$ within r.m.s. deviations of $\sim 0.08 \AA$; in this description, Na1 lies on a center of symmetry [Wyckoff positions $(a)$ ] and $\mathrm{Na} 4$ on a $C_{2}$ axis $[(d)]$; the remaining atoms are in general positions. There is a distinct improvement in the geometry on going from $P c$ to $P 2 / c$. For example, $d(\mathrm{~N}-\mathrm{O})$ of the nitro groups ranges from 1.02 to $1.41 \AA$ in the $P c$ model, but from 1.20 to $1.25 \AA$ in the $P 2 / c$ model. Similarly for $d(\mathrm{~S}-\mathrm{O})(1.38-1.50 \AA$ against $1.43-$ $1.45 \AA)$ and $d(\mathrm{C}-\mathrm{O})(1.31-1.42 \AA$ against $1.35-1.36 \AA)$.

\section{3. (35) RACFEG: catena-(bis(tetramethylammonium) (hexa $\left(\mu^{2}\right.$-cyano)di-iodo-tricadmium) tetrachloroethene clathrate), $\left.\left[\left(\mathrm{Cd}_{3} \mathrm{I}_{1.74}(\mathrm{CN})_{6.26}\right)^{2-}\right] \cdot 2\left[\left(\mathrm{CH}_{3}\right)_{4} \mathrm{~N}\right)\right]^{+} \cdot \mathrm{C}_{2} \mathrm{Cl}_{4}$ (Kitazawa et al., 1992)}

This structure was reported in space group $\mathrm{Cm}[Z=2 ; a=$ 15.467 (7), $b=8.541$ (7), $c=12.84$ (2) $\AA$, $\beta=92.01$ (7) ${ }^{\circ}$ ], but can be transformed to $C 2 / m$ after origin shifts of $\Delta x=$ -0.330 (11), $\Delta \mathrm{z}=-0.691$ (6). This change involves shifting the cell origin from a tetrahedral $\mathrm{Cd}$ atom, $\mathrm{Cd} 1$, to the octahedral $\mathrm{Cd} 3$. The iodines are linked to the tetrahedral $\mathrm{Cd}$ atoms 
and are partially replaced by cyano groups (respective occupancies 0.876:0.124 for both independent I atoms in $\mathrm{Cm}$ ). The diffraction results are in accordance with the non-stoichiometric formulation of the complex based on chemical analysis. Disorder of the methyl groups of the tetramethylammonium cations has not been adequately resolved; the methyls have occupancies of $0.67 \mathrm{in} \mathrm{Cm}$. The disorder is not altered by the change of space group.

\section{4. (36) CHXCUB: bis(cis-1,3-cyclohexanediamine-} $\left.\mathrm{N}, \mathrm{N}^{\prime}\right)$ copper(II) dinitrate, $\left[\mathrm{C}_{12} \mathrm{H}_{28} \mathrm{CuN}_{4}\right]^{2+}\left(\mathrm{NO}_{3}{ }^{-}\right)_{2}$ ) (Kamisawa et al., 1981)

This compound was reported in space group $\mathrm{Cm}[Z=2 ; a=$ 10.059 (3), $b=9.278$ (3), $c=10.428$ (3) $\AA, \beta=117.12(4)^{\circ}$ ], implying that the cation and anions have symmetry $C_{s}-m$, with the cation having virtual $C_{2 h}$ symmetry [see Table 2 and Figs. 1 and $2(b)$ of the original paper]. The authors reported that preliminary refinements in $C 2 / \mathrm{m}, C 2$ and $C m$ led to $R$ values of $0.098,0.118$ and 0.051 , respectively; they chose the latter and report a final $R$ of 0.033 . However, the coordinates agree (with no change of origin) with space group $C 2 / m$ within an r.m.s. deviation of less than $0.02 \AA$. Supplementary data in BCSJ 8120 .

4.5. (37) FOHDUB: $\operatorname{bis}\left(\mu^{2}\right.$-carbonyl)-( $\eta^{5}$-cyclopentadienyl)$\left(\eta^{5}\right.$-pentamethylcyclopentadienyl)cobalt-iridium, $\mathrm{C}_{17} \mathrm{H}_{20} \mathrm{ColrO}_{2}$ (Hörlein et al., 1987)

This compound was reported in space group $\mathrm{Cm}[a=$ 17.305 (5), $b=9.299$ (2), $c=10.2970$ (7) $\AA$, $\beta=93.700^{\circ}$ ]; the unit cell contains four molecules, with two (so-called) independent molecules, of symmetry $m$, in the asymmetric unit. In fact, these two molecules are related by a center of symmetry and the space group is $C 2 / m$; the single molecule in the asymmetric unit has symmetry $m$. The r.m.s. fractional deviations from $C 2 / m$ are $0.0050,0.0075$ and 0.0086 .

\section{6. (38) KOYXOL: bis-guanidinium hexafluorotitanium, $\left[\mathrm{C}\left(\mathrm{NH}_{2}\right)_{3}\right]_{2} \mathrm{TiF}_{6}$ (Calov et al., 1991)}

This compound was reported in space group $\mathrm{Cm}[Z=2 ; a=$ 12.869 (2), $b=7.378$ (4), $c=6.243$ (8) $\AA$, $\beta=114.450$ (3) ${ }^{\circ}$; 'aus der E-Wert-Statistik folgt, daß die Struktur azentrisch ist'), implying that the cation and anions have symmetry $C_{s}-m$. A shift of the origin by $\Delta x=-0.5620, \Delta z=-0.5808$ and averaging gives revised coordinates in space group $C 2 / \mathrm{m}$, with the cation and anion having $C_{2 h}$ symmetry. The fractional r.m.s. deviations from $C 2 / m$ are: $0.0038,0.0023$ and 0.0046 . The misleading $E$ statistics were probably due to the fact that the primitive unit cell contains a single heavy (Ti) atom (Hargreaves, 1955). Bis-guanidinium compounds with anions $\mathrm{SiF}_{6}, \mathrm{GeF}_{6}, \mathrm{SnF}_{6}, \mathrm{NbOF}_{5}$ and $\mathrm{WO}_{2} \mathrm{~F}_{4}$ were reported in this paper to be isostructural. However, Waskowska (1997), who determined the structure of the 'isostructural' Si compound (KOYXUR01) in $C 2 / m$, remarked about KOYXOL: 'The diguanidinium titanium analogue, however, forms a noncentrosymmetric structure, with two symmetrically independent guanidinium cations'. This anomaly now falls away.
4.7. (39) PASQAB: $\left\{\left(C_{60}\right.\right.$-fullerene $)-5,6,11,12$-tetrahydro$5,12\left(1^{\prime}, 2^{\prime}\right): 6,11\left(1^{\prime \prime}, 2^{\prime \prime}\right)$-dibenzenodibenzo(a,e)cyclo-octene\} benzene solvate, $\mathrm{C}_{60} \cdot \mathrm{C}_{28} \mathrm{H}_{20} \cdot 3 \mathrm{C}_{6} \mathrm{H}_{6}$ (Konarev et al., 1997)

This compound was reported in space group $\mathrm{Cm}[a=$ 13.260 (5), $b=15.177$ (4), $c=15.764$ (5) $\AA$, $\left.\beta=110.97(2)^{\circ}\right]$, but can be transformed to $C 2 / \mathrm{m}$. The r.m.s. fractional deviations from $C 2 / m$ are $0.0046,0.0046$ and 0.0043 . The authors note the large spread of $\mathrm{C}-\mathrm{C}$ distances in the fullerene, 1.04-1.84 $\mathrm{\AA}$. This is somewhat reduced in $C 2 / m, 1.23-1.62 \AA$; further refinement is clearly needed.

\section{8. (40) VOKKIP: catena-(potassium cyanurate monohy- drate), $\mathrm{K}^{+}\left(\mathrm{C}_{3} \mathrm{H}_{2} \mathrm{~N}_{3} \mathrm{O}_{3}\right)^{-} \cdot \mathrm{H}_{2} \mathrm{O}$ (Sysoeva et al., 1990)}

This structure was reported in space group $\mathrm{Cm}[Z=8 ; a=$ 11.044 (3), $b=16.390$ (3), $c=7.199$ (2) $\AA, \beta=103.80$ (2) ${ }^{\circ}$ ], with two independent formula units in the asymmetric unit. After an origin shift of $\Delta x=-0.911(4), \Delta z=-0.443$ (5), the coordinates agree with $C 2 / m$ within r.m.s. deviations of $\sim 0.05 \AA$. There are two independent $\mathrm{K}$ cations and two independent water molecules on mirror planes, and two independent cyanurate anions on twofold axes.

\section{9. (41) POWYUV: tetrakis(dimethyldithiocarbamato)tung- sten(V) 7,7,8,8-tetracyano-quinodimethanide, $\left[\mathrm{C}_{12} \mathrm{H}_{24} \mathrm{~N}_{4} \mathrm{~S}_{8} \mathrm{~W}\right]^{+} \cdot\left[\mathrm{C}_{12} \mathrm{H}_{4} \mathrm{~N}_{4}\right]^{-}$(Le Stang et al., 1998)}

This structure was reported in space group $C c[Z=4 ; a=$ 12.894 (2), $b=18.666$ (2), $c=14.059$ (2) $\left.\AA, \beta=91.11(1)^{\circ}\right]$; relations between coordinates show that the correct space group is $C 2 / c(Z=4)$, with fractional r.m.s. deviations from $C 2 / c$ : $0.0038,0.0013$ and 0.0022. LeStang et al. (1998) state '...there is no crystallographically imposed symmetry for the TCNQ species'. In the revised $C 2 / c$ structure of POWYUV the TCNQ anion is located about a center of symmetry, while the tungsten lies on a twofold rotation axis.

4.10. (42) RIDPID: $\mathrm{Ni}(\mathrm{bpy})_{2}\left(\mathrm{CF}_{3} \mathrm{SO}_{3}\right)_{2}$, where bpy is 2,2'bipyridine, $\mathrm{C}_{22} \mathrm{H}_{16} \mathrm{~N}_{4} \mathrm{O}_{6} \mathrm{~F}_{6} \mathrm{~S}_{2} \mathrm{Ni}$ (Aizawa et al., 1995)

The compound was reported in space group $A a$ with cell dimensions $a=18.55$ (1), $b=14.48$ (1), $c=9.941$ (7) $\AA$, $\beta=$ $101.98(3)^{\circ}, Z=4$. Pairs of atoms such as S1, S2 and O1, O4 have the same $y$ coordinates, which is suggestive of a twofold axis. After transformation to the conventional $C$-centered cell, coordinates were averaged according to space group $C 2 / c$ with r.m.s. deviations of $0.03 \AA$ in $x$ and $y, 0.05 \AA$ in $z$; the complex indeed has $C_{2}$ symmetry. As in other examples, the spread in bond lengths [e.g. for $\mathrm{Ni}-\mathrm{N}, 2.029(5)-2.079$ (4) $\AA$ ] is an artifact due to the use of the wrong space group rather than a chemical effect; in the revised structure the $\mathrm{Ni}-\mathrm{N}$ distances are 2.052 and $2.054 \AA$.

4.11. (43) ZAWSUL: ( $N, N^{\prime}$-dibenzyl- $N, N^{\prime}$-di(quinoline-2methyl))-1,2-ethylenediamine at $173 \mathrm{~K}, \mathrm{C}_{36} \mathrm{H}_{34} \mathrm{~N}_{4}$ (Rieger et al., 1995)

The compound was reported in space group $C c, Z=4$, with cell dimensions $a=30.834$ (6), $b=6.361$ (1), $c=17.283$ (3) $\AA$, 
$\beta=123.26(3)^{\circ}$; it was stated that 'all attempts to solve the structure in space group $C 2 / c$ failed'. In fact, after the origin is shifted by $\Delta x=0.082, \Delta z=0.060$, the coordinates are compatible with $C 2 / c$ within r.m.s. deviations of $\sim 0.02 \AA$. There are some printing errors in the published coordinates, but these have been corrected in the CSD.

\subsection{2. (44) ZEDCUG: hexa-tert-butyl benzenehexacarboxy- late, $\mathrm{C}_{36} \mathrm{H}_{54} \mathrm{O}_{12}$ (Yasuda et al., 1994)}

This compound was reported in space group $C c[a=$ $16.632(?),{ }^{9} b=14.074(5), c=16.872$ (4) $\AA, \beta=92.98(1)^{\circ} ; Z=$ 4]. After the origin is shifted by $\Delta x=-0.3205, \Delta z=-0.2142$, the molecule lies on a twofold axis at $x=1 / 2, z=1 / 4$ within r.m.s. deviations of $\sim 0.06 \AA$ in $x, y$ and $z$; the $C_{2}$ axis passes through the midpoints of the $\mathrm{C} 1-\mathrm{C} 2$ and $\mathrm{C} 4-\mathrm{C} 5$ bonds of the benzene ring. For the $C c$ structure, Yasuda et al. (1994) note a 'deformed benzene ring' with aromatic $\mathrm{C}-\mathrm{C}$ distances ranging from 1.28 (1) to 1.49 (1) $\AA$, as well as wide variations in the $\mathrm{C}($ benzene $)-\mathrm{C}($ ester $)$ distances $(1.37-1.67 \AA)$ and in the $\mathrm{C}-\mathrm{CH}_{3}$ distances $(1.43-1.71 \AA$; all s.u.'s $0.01-0.02 \AA)$. The disparities effectively disappear in the $C 2 / c$ description. Supplementary data in BCSJ 67007. We compare below the situation in ZEDCUG and ZEDDAN (tetra-tert-butyl 1,2,4,5benzenetetracarboxylate).

\subsection{3. (45) REFCODE not yet assigned: 6,12-dioxaanthra- cene, ${ }^{10} \mathrm{C}_{20} \mathrm{H}_{10} \mathrm{O}_{2}$ (Asari et al., 2001)}

The structure of this compound was solved in space group $C c[Z=4 ; a=15.928$ (3), $b=4.983$ (3), $c=16.170$ (3) $\AA$, $\beta=$ $\left.91.33(2)^{\circ}\right]$. If the molecule is treated as centrosymmetric, the r.m.s. deviation between pairs of $C c$ bond lengths is $0.062 \AA$, approximately six or seven times as large as the least-squares s.u. of an individual bond length. Furthermore, the sums of coordinates for related pairs of atoms are 1.741 (2) in $x$, 0.503 (7) in $y$ and 0.643 (3) in $z$. Thus, the molecular center may be moved to Wyckoff position $(c)(1 / 4,1 / 4,0)$ in space group $C 2 / c$; coordinates are in Table $45 \mathrm{~S}$ of the supplementary material. Asari et al. (2001) use $C c$ bond lengths averaged across a center for comparison in their Table 2; it would be preferable to carry out further refinement in the centrosymmetric space group.

\subsection{4. (46) No REFCODE as inorganic, $\mathrm{Mo}_{3} \mathrm{Fe}-$ $\mathrm{S}_{4}\left(\mathrm{H}_{2} \mathrm{O}\right)\left(\mathrm{NH}_{3}\right)_{9} \mathrm{Cl}_{4}$ (Shibahara et al., 1995)}

The authors say of this orthorhombic $[a=14.948$ (4), $b=$ $16.233(3), c=9.208(2) \AA ; Z=4]$ structure 'systematic absences uniquely identified the space group as $P 2_{1} c n$ '. After cyclic permutation of the cell axes, giving 9.208, 14.946 and $16.233 \AA$, a satisfactory structure can be found in Pnma, which carries the same absences. The r.m.s. deviations from Pnma for the eight matched atom pairs are $0.05,0.04$ and $0.03 \AA$ in $x, y$ and $z$, which is typical for the 'add a center' situation.

\footnotetext{
${ }^{9}$ Changed by CSD from $16.632(0)$.

${ }^{10}$ Alternative name peri-xanthenoxanthene, hence the acronym PXX (Hjorth et al., 1994).
}

\subsection{5. (47) FOZPAL: pentacarbonyl(phenylisocyanide)rhe-} nium tetrafluoroborate, $\operatorname{ReC}_{12} \mathrm{H}_{5} \mathrm{NO}_{5} \mathrm{BF}_{4}$ (Steil et al., 1988)

This structure was reported in $P n 2_{1} a[Z=4 ; a=15.412$ (5), $b$ $=7.668$ (2), $c=13.038$ (3) $\AA$; $T=223 \mathrm{~K}]$, but the presence of a molecular mirror plane leads to its better description in Pnma. The molecules are in Wyckoff positions (c); the phenyl group, which lies in the mirror plane in Pnma, was constrained to be a regular hexagon in the $P n 2_{1} a$ refinement. The $\mathrm{C}-\mathrm{O}$ distances range from 1.09 to $1.23 \AA$ in $P n 2_{1} a$, but are at $1.13-1.14 \AA$ in Pnma. The $\mathrm{Re}-\mathrm{C}(\mathrm{O})$ distances range from $1.93-2.07 \AA$ in $P n 2_{1} a$ and hence are indistinguishable from $\mathrm{Re}-\mathrm{C}(\mathrm{N})$, while in Pnma they range from 2.00 to $2.03 \AA$ and hence are, as expected, shorter than $\mathrm{Re}-\mathrm{C}(\mathrm{N})(2.08 \AA)$.

4.16. (48) KISNAB: dichloro(6,13-(bis-2-hydroxyethyl)$6 H, 13 H$-tripyrido[cd,fg, Im]-[1,2,4,7,9,10] heptaazapentadecine)iron(III) chloride, $\mathrm{C}_{23} \mathrm{H}_{25} \mathrm{Cl}_{3} \mathrm{FeN}_{7} \mathrm{O}_{2}$ (Constable et al., 1991)

This structure was reported in space group $P n a 2_{1}[a=$ 5.494 (8), $b=12.873$ (6), $c=12.229$ (6) $\AA$; $Z=4$ ]. Figs. 1 and 2 of Constable et al. (1991) suggest that the cation has a mirror plane normal to the mean cation plane, while Fig. 3 suggests that the crystal structure is centrosymmetric. The coordinates in their Table 2 confirm these expectations; the correct space group is Pnma. After an origin shift $\Delta y=-0.105$, the largest deviation from Pnma is for atom C3, which lies $\sim 0.18 \AA$ from the mirror plane. For the $P n a 2_{1}$ structure, $d(\mathrm{C} 2-\mathrm{C} 3)$ and $d(\mathrm{C} 3-\mathrm{C} 4)$ in the pyridine ring are 1.28 and $1.48 \AA$; they are equal (by symmetry) at $1.38 \AA$ in Pnma. Other distances are similarly improved.

\subsection{7. (49) YUFXIG $\left[(\mathrm{CO})_{6} \mathrm{Fe}_{2}(\mu \text {-SeCH})_{2}\right]$ (Mathur et al., 1995)}

This compound was reported in $P c 2_{1} n[a=7.202(1), b=$ 10.544 (1), $c=18.344$ (3) $\AA]$ and is here revised to Pnma, transformation matrix $(00 \overline{1} ; 010 ; 100)$, with a shift of origin $\Delta y=-0.820$ (2). The molecule has a mirror plane running through the two Fe atoms and two carbonyl groups $\mathrm{C} 2-\mathrm{O} 2$ and C5-O5 (see Fig. 4 of Mathur et al., 1995).

\subsection{8. (50) ZUFDIN: $\left[\mathrm{Ni}_{2}(\text { cyclam })_{2}-p\right.$-xyl] $\mathrm{ClO}_{4} \cdot 4 \mathrm{H}_{2} \mathrm{O}$,} (cyclam)2-p-xyl is $a, a^{\prime}$-bis $(1,4,8,11$-tetraazacyclotetradecan6-yl)-p-xylene) (Kido et al., 1995)

This compound was reported in space group $P 4_{2}$ (No. 77), $Z=2[a=15.251$ (2), $c=9.821$ (2) $\AA]$; choice of space group was 'based on the systematic absence $(00 l: l \neq 2 n)$ and the successful solution of the structure'. After a small shift in the origin along c, the structure is compatible with $\mathrm{P}_{2} / m$ within r.m.s. deviations of $\sim 0.05 \AA$; the symmetry of the cation becomes $2 / m$ rather than 2 and the structure is achiral rather than chiral. The coordinates of the atoms of the perchlorate anions and water molecules were not published, and do not appear in the CSD. 
4.19. (51) and (52): LAKRIY, $\mathrm{C}_{12} \mathrm{H}_{10} \mathrm{BMnN}_{6} \mathrm{O}_{3}$, and LAKROE, $\mathrm{C}_{12} \mathrm{H}_{10} \mathrm{BN}_{6} \mathrm{O}_{3}$ Tc (Joachim et al., 1993)

These two compounds are isomorphous and were reported in space group $P 3$ (No. 143), $Z=2[a=11.522$ (4), $c=7.933$ (3) $\AA$ for LAKRIY and $a=11.464(4), c=8.091$ (3) $\AA$ for LAKROE]. The structures were solved with 'zwei unabhängigen Molekülen pro Elementarzelle'. These were located at Wyckoff positions $(b)$ and $(c)$, both with symmetry 3 ; Joachim et al. (1993) do not justify the choice of $P 3$ from the eight trigonal possibilities (two different Laue groups) with 'no reflection conditions'. Apparently there were severe refinement difficulties in $P 3$ as the shift/error values were 6.68 and 3.38 for LAKRIY and LAKROE, respectively. A packing diagram of the unit cell shows that the two purportedly independent molecules are related by a center of symmetry at $\frac{1}{2}, \frac{1}{2}, 0$ in space group $P \overline{3}$ (No. 147), Wyckoff positions $(d)$, site symmetry 3. As noted by Joachim et al. (1993), the molecular symmetry is approximately $3 m$. There is also an isomorphous Re compound $[a=11.466$ (2), $c=8.037$ (3) $\AA$ ], but the full structure was not reported.

4.20. (53)ZATGIK: In'"'(DEHP) $)_{3} \cdot 3 \mathrm{H}_{2} \mathrm{O}$, where DEPH is $1,2-$ diethyl-3-hydroxy-4-pyridinone $\left(\mathrm{C}_{9} \mathrm{H}_{13} \mathrm{NO}_{2}\right), \mathrm{C}_{27} \mathrm{H}_{42} \mathrm{~N}_{3} \mathrm{O}_{9}$ In (Ma et al., 1994)

This structure was originally reported as rhombohedral, space group $R 3$, with $a=15.447$ (3), ${ }^{\mathbf{1 1}} c=23.026$ (5) $\AA, Z=6$ units of $\mathrm{C}_{27} \mathrm{H}_{42} \mathrm{~N}_{3} \mathrm{O}_{9}$ In $3 \mathrm{H}_{2} \mathrm{O}$. Ma et al. (1994) noted that 'the $\delta$ and $\lambda$ isomers of $\left[\mathrm{In}^{\mathrm{III}}(\mathrm{DEHP})_{3} \cdot 3 \mathrm{H}_{2} \mathrm{O}\right]$ crystallize in space group $R 3$ with the $\mathrm{In}^{\mathrm{III}}$ atoms located on crystallographic threefold axes.... The two isomers may be related by a pseudoinversion center'. It was further remarked that both noncentrosymmetric $R 3$ and centrosymmetric (sic) $R 3 m$ were compatible with the systematic absences, the former being preferred on the basis of intensity statistics and better refinement results. The absolute structure was determined [Flack parameter 0.05 (6) in their Table 1]; in the light of what follows, this has no meaning. The two metal complexes in the asymmetric unit are related, within r.m.s. deviations of $\sim 0.03 \AA$, by a center of inversion at $(1 / 6,-1 / 6,0.293)$; after translation to the conventional origin, the In atoms lie on Wyckoff positions $(c)(00 z, 00 \bar{z}$; symmetry 3$)$ of space group $R \overline{3}$.

We make some comments about the role of the water molecules in the structure. There are two structurally distinct types, labeled O5 and ${ }^{\mathbf{1 2}}$ in Table 5 of Ma et al. (1994). In the original, $R 3$ description, three W5 atoms are apparently hydrogen-bonded together $[d(\mathrm{~W} 5 \cdots \mathrm{W} 5)=2.98 \AA]$, forming an equilateral triangle around a $C_{3}$ axis; these waters also donate hydrogen bonds $[d(\mathrm{~W} 5 \cdots \mathrm{O} 1)=2.82 \AA]$ to an oxygen atom $\mathrm{O} 1$ of one, but not the other, of the two independent metal complexes. (The corresponding atom in the second complex, O4, has no donor.) The three W6 water molecules

\footnotetext{
$\mathbf{1 1}$ The calculated volume shows that the value of 15.477 (3) $\AA$ given for $b$ in Table 1 is a misprint. Minimum and maximum values of 0.9876 and 0.9999 for the absorption correction suggest that reconsideration is necessary.

${ }^{\mathbf{1 2}}$ Here renamed W5 and W6 for clarity.
}

are not hydrogen-bonded together; they are separated by $4.05 \AA$. Instead, they appear to form two hydrogen bonds apiece to oxygen atoms $\mathrm{O} 2(3.06 \AA)$ and to $\mathrm{O} 3(2.82 \AA)$ of different complexes. In this $R 3$ structure, the two types of water molecules are not paired across the symmetry center of $R \overline{3}$; we must presume that in the difficulties associated with refining the structure as non-centrosymmetric, the mates were overlooked. For W5 this seems highly likely, as there is no reason to expect $\mathrm{O} 1$ of one metal complex to be hydrogen bonded while its pseudo-symmetrically (at least) related counterpart $\mathrm{O} 4$ is not. In the case of W6, the additional center in $R \overline{3}$ would create a nearly planar hexagon with $\mathrm{O} \cdots \mathrm{O}$ distances improbably short at $2.35 \AA$ A. However, we note that this atom has a very large displacement parameter, with $U=$ $0.33 \AA^{2}$, suggesting that its site may be only partially occupied. We further note that neither a chemical analysis nor a density measurement is available to establish the amount of water in the crystal (nor is there evidence that the crystals lost water during data collection). It seems likely that the composition differs from that reported, perhaps corresponding to approximately 4.5 water molecules per complex rather than 3 ; but we can only conjecture.

4.21. (54) PAMCOV: [tris(ruthenium $(\mathrm{III})\left(\mu_{3}-\mathrm{O}\right)$ hexakis $(\mu$ benzoate- $\left.O, O^{\prime}\right)$ tris $(N$-pyridine)] hexafluorophosphate (Abe et al., 1992)

This compound was reported in the chiral space group $P 6_{3}$ (No. 173) $[a=13.619$ (6), $c=19.204$ (9) $\AA$; $Z=2$ ], but is better described in the centrosymmetric space group $P 6_{3} / m$ (No. 176). In the revised description, the central $\mu_{3}$-oxygen of the ruthenium cation lies on a site of symmetry $\overline{6}$ rather than symmetry 3 , and the octahedral $\mathrm{PF}_{6}{ }^{-}$anion has symmetry $\overline{3}$. In the $P 6_{3}$ structure the bond lengths vary around the ring [starting from $\mathrm{N}: 1.45(3)(\mathrm{N}-\mathrm{C}), 1.48(3), 1.43(5), 1.31(4)$, $1.34(2), 1.27(2) \AA(\mathrm{N}-\mathrm{C})]$, while the mirror-plane paired values are close to standard $[1.35(\mathrm{C}-\mathrm{N}), 1.41,1.37 \AA]$ in the $P 6_{3} / m$ structure.

\section{Category C: add a center of symmetry and systematic absences}

5.1. (55) KERGET: cis-transoid-cis-cyclobuta(1,2-a;3,4-a')diindene, $\mathrm{C}_{18} \mathrm{H}_{16}$ (Shima et al., 1989)

This structure was reported in space group $P 2_{1}[a=$ 7.162 (2), $b=6.320$ (3), $c=13.647$ (2) $\AA$, $\left.\beta=97.60(8)^{\circ} ; Z=2\right]$. The molecule appears to be centrosymmetric in their Figs. 2 and 3. After an origin shift of $-1 / 4,-0.59,-3 / 4$, the molecule is located about a center of symmetry in space group $P 2_{1} / n$ within r.m.s. deviations of $\sim 0.03 \AA$. The reflection condition ' $h 0 l$ absent for $h+l$ odd' was not recorded. Supplementary data in BCSJ 8874. The dihedral angle of the cyclobutane ring, given as $3^{\circ}$ in $P 2_{1}$, must be zero (by symmetry) in $P 2_{1} / n$. 


\section{2. (56) LEVJUR: $\left(\mathrm{C}_{5} \mathrm{Me}_{5}\right) \mathrm{Ta}\left(\mathrm{S}-{ }^{t} \mathrm{Bu}\right)_{3}\left(\mathrm{O}-{ }^{n} \mathrm{Bu}\right), \mathrm{C}_{26} \mathrm{H}_{51} \mathrm{OS}_{3} \mathrm{Ta}$} (Tatsumi et al., 1994)

This compound was reported in $P 2_{1}, Z=4[a=9.134$ (4), $b=$ $12.078(7), c=27.74(2) \AA, \beta=92.39(6)^{\circ}$ ]. It was stated that 'inspection of the systematic absences indicated possible space groups $P 2_{1}$ and $P 2_{1} / \mathrm{m}$. The mean $E^{2}-1$ value and packing considerations suggested non-centric $P 2_{1}$, and the successful solution and refinement of the structure support the choice as the correct space group'. Thus, it was concluded that there were two crystallographically independent molecules in the asymmetric unit, with different $\mathrm{Ta}-\mathrm{O}-\mathrm{C}$ angles of 133.2 (7) and $159.6(7)^{\circ}$, different $\mathrm{Ta}-\mathrm{O}$ bonds $[1.919(7)$ and 1.856 (6) $\AA$ )] and different $\mathrm{Ta}-\mathrm{S}$ bonds. There was appreciable theoretical discussion of these differences, but not of the $\mathrm{C}-\mathrm{C}$ distances within the cyclopentadiene rings, which varied from 1.28 to $1.68 \AA$. However, the two molecules are related, within r.m.s. deviations of $\sim 0.07 \AA$, by a $c$-glide plane at $y=$ 0.0114 ; a shift in origin of 0.2386 in $y$ leads to the proper space group $P 2_{1} / c$. The reflection condition ' $h 0 l$ absent for $l$ odd' was not recognized. The revised coordinates give $\angle \mathrm{Ta}-\mathrm{O}-\mathrm{C}=$ $146.0^{\circ}$ and ring $\mathrm{C}-\mathrm{C}$ from 1.38 to $1.53 \AA$, still a large spread in view of the reported e.s.d.'s of $\sim 0.02 \AA$.

\section{3. (57) ZEDDAN: tetra-tert-butylbenzenetetracarboxylate, $\mathrm{C}_{26} \mathrm{H}_{38} \mathrm{O}_{8}$ (Yasuda et al., 1994)}

This structure was reported in space group $P 2_{1}, Z=2[a=$ 11.696 (3), $b=10.450$ (5), $c=11.176$ (5) $\AA$, $\beta=95.14$ (2) ${ }^{\circ}$; no molecular symmetry is required. The coordinates can be translated $(\Delta x=-1 / 2, \Delta y=-0.1682, \Delta z=-1 / 4)$ so that the molecule is located centrosymmetrically about the origin of the unit cell; the space group is now $P 2_{1} / c$. This implies that the reflection condition, $h 0 l$ absent for $l$ odd, was not recognized. We have checked this by obtaining the supplementary data from BCSJ 67007. There are approximately $5500 \mathrm{~F}$ values, covering a hemisphere. One can predict that there should be approximately $95 h 0 l$ reflections with $l$ odd; 14 of these are included in the $F$ table. All are very weak; the strongest, 101, at 2.4 electrons would have an intensity of $\sim 3 \times 10^{-4}$ that of 102 (150 e). This confirms the space group revision. Thus, in ZEDDAN, the molecule is located at a crystallographic center of symmetry in $P 2_{1} / c$ rather than being an approximately centrosymmetric molecule in a general position in $P 2_{1}$ (cf. Marsh, 1986, and elsewhere). In the $P 2_{1} / c$ structure, all equivalent pairs of bond lengths (seven pairs plus a benzene ring) agree within $0.01 \AA$. In the original $P 2_{1}$ structure, agreement was considerably worse: for example, the $\mathrm{C}-$ $\mathrm{C}$ (methyl) bonds (12 of them) ranged from 1.45 to $1.58 \AA$; in $P 2_{1} / c$, the six values range from 1.50 to $1.52 \AA$.

We note that ZEDDAN and ZEDCUG (see above) are related compounds, described in the same publication. The

\footnotetext{
13 Yasuda et al. (1994) write 'differences in the bond lengths/angles in ZEDCUG and ZEDDAN are impressive. The mean bond length and angle of the benzene ring do not significantly differ in ZEDCUG and ZEDDAN, but the individual bond lengths/angles deviate much more extensively from the mean values in the highly congested hexaester ZEDCUG. Thus, the bond lengths and angles in ZEDCUG vary fairly widely from 1.28 to $1.49 \AA$ and from 110 to $129^{\circ}$,
}

authors (Yasuda et al., 1994) comment extensively on the wide variations in bond lengths and angles in these compounds, and discuss them as physically meaningful. ${ }^{\mathbf{1 3}}$ However, most of the variations are due to the mis-assignment of space groups; when the coordinates are averaged across the added centers of symmetry, the variations nearly disappear.

5.4. (58) CADKUN: ( $N, N^{\prime}$-dibenzyl-4-methyl-4-azaheptane1,7-diamine)(dimethylformamide) $\left(\mathrm{BF}_{4}\right) 2, \mathrm{PdF}_{8} \mathrm{ON}_{4} \mathrm{C}_{24} \mathrm{~B}_{2} \mathrm{H}_{38}$ (Yagyu et al., 1998)

This structure was reported in space group $\operatorname{Pn}[Z=4 ; a=$ 21.173 (4), $b=13.096$ (2), $c=10.826$ (2) $\left.\AA, \beta=102.07(1)^{\circ}\right]$. The corresponding atoms of the two purportedly independent molecules are related by a $2_{1}$ axis parallel to b. After the origin is shifted by $\Delta x=0.131, \Delta y=0.25, \Delta z=0.181$, the space group becomes $P 2_{1} / n$ within r.m.s. deviations of $\sim 0.05 \AA$. The reflection condition ' $0 k 0$ absent for $k$ odd' was missed. Although the $\mathrm{F}$ atoms of the tetrafluoroborate groups have $B_{\text {eq }}$ factors ranging from 8.6 to $22 \AA^{2}$, they average satisfactorily. In the $P n$ structure the $\mathrm{B}-\mathrm{F}$ bonds range from 1.20 to $1.47 \AA$, whereas the range in the revised structure is 1.29 1.36 A. Supplementary data in BCSJ 71010 .

\section{5. (59) KUSLOZ: bis(2-(dimethylphosphino)ethane-1-thio- lato)nickel(II), $\mathrm{C}_{8} \mathrm{H}_{20} \mathrm{NiP}_{2} \mathrm{~S}_{2}$ (Kita et al., 1992)}

This compound was reported in space group $\operatorname{Pn}[a=$

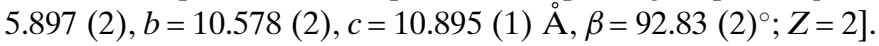
Fig. 1 of Kita et al. (1992) suggests that the molecule is centrosymmetric. Shifts of $\Delta x=-0.6112, \Delta y=-0.25, \Delta z=$ -0.0570 applied to the published coordinates (their Table 1) place the $\mathrm{Ni}$ atom at the origin, with the other atoms paired as $x, y, z ;-x,-y,-z$. The coordinates in $P 2_{1} / n$ have r.m.s. deviations of $0.05 \AA$ in $x, 0.03 \AA$ in $y$ and $0.02 \AA$ in $z$. The reflection condition ' $0 k 0$ absent for $k$ odd' was not recognized. Supplementary data are in BCSJ 9016.

\section{6. (60) TOSSAV: $\left[\left(\mathrm{SnMe}_{2}\right)_{2}(\mathrm{edta})\left(\mathrm{H}_{2} \mathrm{O}\right)_{2}\right] \cdot \mathrm{H}_{2} \mathrm{O}$, $\mathrm{Sn}_{2} \mathrm{O}_{11} \mathrm{~N}_{2} \mathrm{C}_{14} \mathrm{H}_{30}$ (Aizawa et al., 1996)}

The space group was reported as $P c, Z=4$ [cell dimensions

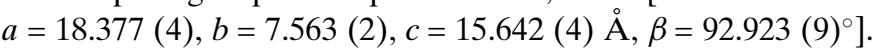
The ORTEP diagram of Fig. 4 of Aizawa et al. (1996) strongly suggests that the molecule is centrosymmetric and this is confirmed by pairing atomic coordinates. The reflection condition $0 k 0$ absent for $k$ odd was not recognized. The r.m.s. deviations from $P 2_{1} / c$ are $0.035,0.048$ and $0.041 \AA$. Supplementary data in BCSJ 71070.

\section{7. (61) VOZVIP: 6-methyl-4-(morpholinomethyl)-2H-1- benzothiopyran-2-one, $\mathrm{C}_{15} \mathrm{H}_{17} \mathrm{NO}_{2} \mathrm{~S}$ (Nakazumi et al., 1992)}

This structure was solved in space group $P c, Z=4[a=$ 11.336 (4), $b=16.871$ (7), $c=7.287$ (5) $\AA, \beta=80.748$ (42) $)^{\circ}$ ], but can be transformed to $P 2_{1} / c$ after an origin transformation of $\Delta x=-0.588$ (4), $\Delta y=-3 / 4, \Delta z=-0.577$ (4); we have retained the acute value for $\beta$ to avoid confusion. The reflection condition ' $0 k 0$ absent for $k$ odd' was not recognized; Nakazumi et al. (1992) remark that '...compound $\mathbf{5 f}$ included 
two crystallographically independent molecular units...which showed different bond lengths...'. There is only one molecule in the asymmetric unit after revision. In the $P c$ structure the $\mathrm{C}-\mathrm{C}$ distances within the two benzene rings ranged from 1.24 to $1.53 \AA$; in the $P 2_{1} / c$ structure the $\mathrm{C}-\mathrm{C}$ distances within the single benzene ring range from 1.38 to $1.40 \AA$.

5.8. (62) NALCIM $\left(\mu^{2}-a, a^{\prime}\right.$-bis((di-2-pyridyl)methylamino)- $m$ xylene)bis $\left(\mu^{2}\right.$-hydroxo $)\left(\mu^{2}\right.$-perchlorato-O, $\left.O^{\prime}\right) \operatorname{dicopper}($ II) perchlorate monohydrate, $\left[\mathrm{C}_{30} \mathrm{H}_{26} \mathrm{ClCu}_{2} \mathrm{~N}_{6} \mathrm{O}_{6}\right]^{+}\left[\mathrm{ClO}_{4}\right]^{-} \cdot \mathrm{H}_{2} \mathrm{O}$ (Garcia et al., 1996)

This structure was reported in the enantiomorphous space group $P 2_{1} 2_{1} 2_{1}$ (No. 19), $Z=4$ [ $a=14.188$ (4), $b=14.275$ (3), $c=$ 16.763 (4) $\AA$ ]. After reorientation (transformation matrix 001; $100 ; 010)$ and an origin shift of 0.25 in $y$, atoms are paired in accordance with the centrosymmetric space group Pnma (No. 62) within r.m.s. deviations of $\sim 0.05 \AA$. Garcia et al. (1996) remark (copied by the CSD) that the '... correctness of the absolute structure was confirmed by refinement of Flack's parameter. This parameter, which ought to be zero (within e.s.d.s) for the right structure, came out to be 0.04 (12) for the finally reported data, and 0.91 (12) for its enantiomorph'. Of course, there is no absolute structure ( $c f$. Flack \& Bernardinelli, 1999, 2000). The molecule has a mirror plane passing through O1, O2, C30, C26 (see Fig. 3 of Garcia et al., 1996). The reflection conditions ' $0 k l, k+l=2 n$, and $h k 0, h=2 n$ ' (in the original cell setting) were not recognized. The crystals contain two types of perchlorate, a non-coordinated anion and a loosely coordinated bridging moiety. Garcia et al. (1996) introduced disorder in the refinement of these groups. The major component of the bridging moiety ( $75 \%$ occupancy) is well accounted for by our revised model, as is the $\mathrm{Cl}$ of the anion, while the other (oxygen) positions are less well defined.

\section{9. (63) DIXVOV: trichloro-bis(3-methylimidazole-2-thione- S)antimony(III), $\mathrm{C}_{8} \mathrm{H}_{12} \mathrm{~N}_{4} \mathrm{Cl}_{3} \mathrm{~S}_{2} \mathrm{Sb}$ (Berges et al., 1985)}

The structure was originally reported in space group $P c a 2_{1}$ (No. 29), $Z=8$. The structure factors were acquired from the Microfiche version of the paper. Only $11 h k 0$ reflections with $k$ odd were included; the strongest of these reflections had $F_{\text {obs }}=$ 15.7 electrons, whereas the smallest $F_{\text {obs }}$ in the rest of the table was 10.7 e. We have refined the structure in space group Pbca [cell dimensions in this standard orientation: 9.738 (2), 23.630 (7), 13.584 (4) $\AA$ ] to a final $R$ of 0.041 (2628 reflections; methyl $\mathrm{H}$ atoms disordered), the same as obtained in the original study but with approximately half as many parameters. The centrosymmetric dimeric unit is shown in Fig. 5 of Berges et al. (1985). The r.m.s. difference between paired $\mathrm{Sb}-$ $\mathrm{Cl}$ bonds in $P c a 2_{1}$ is $0.04 \AA$, about seven times the leastsquares standard uncertainty. In the revised structure the three $\mathrm{Sb}-\mathrm{Cl}$ distances are 2.469 (2), 2.618 (2) and 2.782 (2) $\AA$. The largest difference between chemically equivalent bond lengths in the organic rings in the $P c a 2_{1}$ structure was $0.15 \AA$, whereas, after revision, these bonds agree within $0.03 \AA$.

\section{Discussion}

The earliest of our examples was published in 1971, the latest in 2001. Approximately 30\% (19 out of 64) have publication dates 1996 or later. The sample size is far too small to permit conclusions concerning a trend with time.

It is probable that most of the Category A errors occurred early in the diffraction experiment. As far as we can tell, in all but one case the unit cell was derived from a small number, typically 25 or fewer, of reflections centered on a serial diffractometer; the apparent shape of this cell (perhaps the reduced cell, perhaps not) was quite likely the determining factor in assigning the crystal system and the Laue symmetry, without regard to the symmetry of the diffraction intensities or to the fact that the errors in the cell dimensions might have been considerably larger than the estimates of precision. Once the crystal class was selected, it appears as though insufficient effort was made to confirm the Laue symmetry. In one case, example No. 3, the cell parameters were obtained from all observed reflections collected on an area detector diffractometer; the authors chose a triclinic cell and Laue symmetry apparently without taking notice of the fact that two of the angles were insignificantly different from $90^{\circ}$. There are four examples, 26, 28, 29 and 30, where the unit cell was correct, but the wrong Laue group was selected.

Is help on the way? Can we can hope that Category A errors are an endangered species? Most modern diffraction installations include cell-search routines that provide the user with extensive information concerning Niggli cells and possible lattice types. Area detector devices can rapidly survey almost the entire sphere of reflections, which should increase the reliability of the unit cell angles; software is now available for the routine examination of the quality of intensity matching, $R$ (merge), for all possible Laue symmetries. Some programs may even recommend a choice of Laue group (and, perhaps, of space group as well), and accept this choice as a default value unless instructed otherwise. However, the user, not the software, is the responsible party and it is the user who must make the final choice, taking into account the frailties of both software and hardware as well as other relevant circumstances. While not wishing to be thought Luddite, we note that the obsolescent practice of photographing the reciprocal lattice under controlled orientation conditions generally gives unambiguous information about crystal lattice and spacegroup symmetry.

Avoiding Category B and Category C errors is more difficult and also probably more important because of the problem of near-singularities and the distortions to the molecular geometry which usually result. An attempt to decide, early in a diffraction experiment, whether or not the structure is centrosymmetric on the basis of intensity statistics alone is fraught with danger; such statistical tests are often unreliable for several well documented reasons. Even deciding whether special categories of reflections are present or absent may be uncertain, because of difficulties in measuring and assigning error estimates to the intensities of weak or missing reflections. In such cases, a search for possible centrosymmetry is 
best made on the basis of the completed structure determination, by examining drawings of the structure or by surveying the lists of atom coordinates, displacement parameters, and interatomic distances and angles.

We have encountered a number of borderline situations where the evidence favoring possible higher symmetry is equivocal. We have not included such examples, despite their inherent interest, because it is difficult to reach convincing conclusions in the absence of the primary intensity data. This reinforces a plea (Dunitz et al., 1998) for adequate archiving of such data, as is now performed by the International Union of Crystallography and the Chemical Society of Japan.

We have also encountered several examples where authors have justified retention of a non-centrosymmetric space group because of unsatisfactory refinement in the centrosymmetric alternative, whereas repetition of the refinement (based on the same intensity data) by other investigators has not led to any problems. In some cases the original authors used the 'significance test' of Hamilton (1964) as a guide, without carefully considering the assumptions involved; in other cases, we suspect that errors were made in transforming from the lower to the higher symmetry. In addition, Flack \& Bernardinelli $(1999,2000)$ have noted examples where incorrect usage and interpretation of the 'Flack parameter' have led to the fictional assignment of chirality to an achiral structure. In all these cases, as in all the Category B and Category C examples reported here, strong support for the centrosymmetric descriptions came from the much more reasonable interatomic distances and angles that resulted.

There are reasons to hope that errors of this type are on the decline. Structure-checking programs, such as MISSYM (LePage, 1987, 1988) and PLATON/ADDSYM (Spek, 2001), are being incorporated into software packages. Journals of the International Union of Crystallography undertake routine symmetry checks on all submitted manuscripts; we trust that other journals will soon follow suit. However, such checks are no more than guides; it is the investigator who must make the final decision whether the higher symmetry is real or only approximate. The mantra should surely be: examine the input data critically and the output results even more critically.

We end with hope and confidence that papers such as this will become increasingly rare, because of a lack of appropriate examples.

Note added in proof: See \$3.12. We have now noted a recent independent investigation of this structure [Cini, R. \& Cavaglione, A. (1999). Inorg. Chem. 38, 3751-3754], which is included in the October 2001 release of the CSD under the Refcode WABKO201. The space group is confirmed as $C 2 / c$ and the coordinates agree with ours within r.m.s. deviations of $\sim 0.010 \AA$. These authors also note that the earlier $P \overline{1}$ description is compatible with $C 2 / c$.

The possibility that ZEDCUG and ZAWSUL might have symmetries higher than $C c$ was originally pointed out to one of the authors (REM) by Dr Anthony Spek in 1997 (private communication). We are grateful to Professor Dr Jürgen Kopf
(Hamburg) for information about DIXVOV. The staff of the CCDC have been very helpful in providing information.

\section{References}

Abe, M., Sasaki, Y., Yamaguchi, T. \& Ito, T. (1992). Bull. Chem. Soc. Jpn, 65, 1585-1590.

Aizawa, S.-I., Natsume, T., Hatano, K. \& Funahashi, S. (1996). Inorg. Chim. Acta, 248, 215-224.

Aizawa, S.-I., Yagyu, T., Kato, K. \& Funahashi, S. (1995). Analyt. Sci. 11, 557-562.

Andrews, L. C., Bernstein, H. J. \& Pelletier, G. A. (1980). Acta Cryst. A36, 248-252.

Arnold, H. (1983). International Tables for Crystallography, edited by Th. Hahn, Vol. A, Section 5, pp. 69-79. Dordrecht: Kluwer Academic Publishers.

Asari, T., Kobayashi, N., Naito, T. \& Inabe, T. (2001). Bull. Soc. Chem. Jpn, 74, 53-58.

Balakaeva, T. A., Gorbunova, Yu. E., Kurbakova, A. P., Mikhailov, Yu. N. \& Efimenko, I. A. (1994). Russ. J. Coord. Chem. 20, 888-892.

Baur, W. H. \& Tillmanns, E. (1986). Acta Cryst. B42, 95-111.

Baur, W. H. \& Kassner, D. (1992). Acta Cryst. B48, 356-359.

Berges, P., Hinrichs, W., Kopf, J., Mandak, D. \& Klar, G. (1985). J. Chem. Res. pp. 218-219.

Bodige, S. G., Zottola, M. A., McKay, S. E. \& Blackstock, S. E. (1999). Cryst. Eng. 1, 243-253.

Brand, U. \& Vahrenkamp, H. (1992a). Inorg. Chim. Acta, pp. 198-200. Brand, U. \& Vahrenkamp, H. (1992b). Inorg. Chim. Acta, pp. $663-$ 669.

Cabeza, J. A., Martinez-Garcia, M. A., Riera, V., Garcia-Granda, S. \& Ardura, D. (1996). J. Organomet. Chem. 525, 133-138.

Calov, U., Schneider, M. \& Leibnitz, P. (1991). Z. Anorg. Allg. Chem. 604, 77-83.

Cambridge Structural Database (2001). Cambridge Crystallographic Data Centre, 12 Union Road, Cambridge, England.

Constable, E. C., Khan, M. S., Lewis, J., Liptrot, M. C. \& Raithby, P. R. (1991). Inorg. Chim. Acta, 181, 207-212.

Dunitz, J. D., Herbstein, F. H. \& Marsh, R. E. (1998). IUCr Newsl. 6, 6. Fait, J. F., Fitzgerald, A., Caughlan, C. N. \& McCandless, F. P. (1991). Acta Cryst. C47, 332-337.

Fawcett, J., Holloway, J. H. \& Saunders, G. C. (1992). Inorg. Chim. Acta, 202, 111-113.

Filippou, A. C., Wössner, A. D., Kociok-Köhn, G., Hinz, I. \& Gruber, L. (1997). J. Organomet. Chem. 532, 207-218.

Flack, H. D. \& Bernardinelli, G. (1999). Acta Cryst. A55, 908-915.

Flack, H. D. \& Bernardinelli, G. (2000). J. Appl. Cryst. 33, 1143-1148.

Fluck, E., Förster, J.-E., Weidlein, J. \& Hädicke, E. (1977). Z. Naturforsch. Teil B, 32, 499-506.

Garcia, A. M., Manzur, J., Garland, M. T., Baggio, R., Gonzalez, O., Pena, O. \& Spodine, E. (1996). Inorg. Chim. Acta, 248, 247-255,

Gradoz, P., Baudry, D., Ephritikhine, M., Lance, M., Nierlich, M. \& Vigner, J. (1994). J. Organomet. Chem. 466, 107-118.

Hahn, F. E., Tamm, M., Imhof, L. \& Lügger, T. (1996). J. Organomet. Chem. 526, 149-155.

Hamilton, W. C. (1964). Statistics in Physical Science, pp. 157-162. New York: The Ronald Press Co.

Harata, K., Uekama, K., Otagiri, M. \& Hirayama, F. (1987). Bull. Chem. Soc. Jpn, 60, 497-502.

Hargreaves, A. (1955). Acta Cryst. 8, 12-14.

Herbstein, F. H. (1997). Acta Cryst. B53, 968-975.

Herbstein, F. H. (2000). Acta Cryst. B56, 547-557.

Herbstein, F. H. \& Kapon, M. (1985). Z. Kristallogr. 173, 249-256.

Herbstein, F. H. \& Marsh, R. E. (1998). Acta Cryst. B54, 677-686.

Hjorth, M., Thorup, N., Frediriksen, P. \& Bechgaard, K. (1994). Acta Chem. Scand. 48, 139-143.

Hörlein, R., Herrmann, W. A., Barnes, C. E., Weber, C., Krüger, C., Ziegler, M. L. \& Zahn, T. (1987). J. Organomet. Chem. 321, 257272 . 
Ito, M., Sakai, K., Tsubomura, T. \& Takita, Y. (1999). Bull. Chem. Soc. Jpn, 72, 239-247.

Joachim, J. E., Apostolidis, C., Kanellakopulos, B., Maier, R., Marques, N., Meyer, D., Müller, J., Pires de Matos, A., Nuber, B., Rebizant, J. \& Ziegler, M. L. (1993). J. Organomet. Chem. 448, 119129.

Jogun, K. H., Stezowski, J. J., Fluck, E. \& Weidlein, J. (1978). Phosphorus Sulfur, 4, 199-204.

Kamisawa, K., Matsumoto, K., Ooi, S., Saito, R. \& Kidani, Y. (1981). Bull. Chem. Soc. Jpn, 54, 1072-1076.

Katano, N., Sugihara, Y., Ishii, A. \& Nakayama, J. (1998). Bull. Chem. Soc. Jpn, 71, 2695-2700.

Kido, H., Takada, M., Suwabe, M., Yamaguchi, T. \& Ito, T. (1995). Inorg. Chim. Acta, 228, 133-138.

Kita, M., Yamamoto, T., Kashiwabara, K. \& Fujita, J. (1992). Bull. Chem. Soc. Jpn, 65, 2272-2274.

Kitajima, N., Koda, T., Hashimoto, S., Kitagawa, T. \& Moro-oka, Y. (1991). J. Am. Chem. Soc. 113, 5664-5671.

Kitazawa, T., Nishikiori, S. \& Iwamoto, T. (1992). Mater. Sci. Forum, 91-93, 257-264.

Konarev, D. V., Valeev, E. F., Slovokhotov, Y. L., Shul'ga, Y. M. \& Lyubovskaya, R. N. (1997). J. Chem. Res. pp. 442-443.

Lee, W.-B., Suen, S.-C., Jong, T.-T., Hong, F.-E., Chen, J.-H., Lin, H.-J. \& Hwang, L.-P. (1993). J. Organomet. Chem. 450, 63-66.

LePage, Y. (1987). J. Appl. Cryst. 20, 264-269.

LePage, Y. (1988). J. Appl. Cryst. 21, 983-984.

Le Stang, S., Conan, F., Sala Pala, J., Le Mest, Y., Garland, M.-T., Baggio, R., Faulques, E., Leblanc, A., Molinié, P. \& Toupet, L. (1998). J. Chem. Soc. Dalton Trans. pp. 489-496.

Ma, R., Reibenspies, J. J. \& Martell, A. E. (1994). Inorg. Chim. Acta, 223, 21-29.

Makedonopoulou, S., Papaionnou, J., Argyroglou, J. \& Mavridis, I. M. (2000). J. Incl. Phenom. Macrocycl. Chem. 36, 191-215.

Makitova, D. D., Tkachev, V. V., Mizoev, R. S. \& Karov, Z. G. (1989). Koord. Khim. 15, 1334-1339.

Marsh, R. E. (1981). Acta Cryst. B37, 1985-1988.

Marsh, R. E. (1986). Acta Cryst. B42, 193-198.

Marsh, R. E. (1994). Acta Cryst. A50, 450-455.

Marsh, R. E. (1995). Acta Cryst. B51, 897-907.

Marsh, R. E. (1997). Acta Cryst. B53, 317-322.

Marsh, R. E. (1999). Acta Cryst. B55, 931-936.

Marsh, R. E. \& Bernal, I. (1995). Acta Cryst. B51, 300-307.

Marsh, R. E. \& Herbstein, F. H. (1988). Acta Cryst. B44, 77-88.

Mathur, P., Trivedi, R., Hossain, Md. M., Tavale, S. S. \& Puranik, V. G. (1995). J. Organomet. Chem. 491, 291-294.

Mavridis, I. M. \& Hadjoudis, E. (1992). Carbohydr. Res. 229, 1-15.

Michalska, D., Morzyk, B., Wojciechowski, W. \& Glowiak, T. (1996). Inorg. Chim. Acta, 248, 159-166.

Michelin, R. A., Belluco, U., Mozzon, M., Berin, P., Bertani, R., Benetello, F., Bombieri, G. \& Angelici, R. J. (1994). Inorg. Chim. Acta, 220, 21-33.

Mikuriya, M., Jie, D., Kakuta, Y. \& Tokii, T. (1993). Bull. Chem. Soc. Jpn, 66, 1132-1139.
Mikuriya, M., Nakadera, K. \& Kotera, T. (1996). Bull. Chem. Soc. Jpn, 69, 399-405.

Nakano, C., Mori, T., Imaeda, K., Yasuoka, N., Maruyama, Y., Inokuchi, H., Iwasawa, N. \& Saito, G. (1992). Bull. Chem. Soc. Jpn, 65, 1878-1883.

Nakashima, M., Mikuriya, M. \& Muto, Y. (1985). Bull. Chem. Soc. Jpn, 58, 968-973.

Nakazumi, H., Kobara, Y. \& Kitao, T. (1992). J. Heterocycl. Chem. 29, 135-139.

Nogami, T., Shigihara, Y., Matsuda, N., Takahashi, Y., Naganawa, H., Nakamura, H., Hamada, M., Muraoka, Y., Takita, T., Iitaka, Y. \& Takeuchi, T. (1990). J. Antibiot. 43, 1192-1194.

Prozorovskii, A. E., Tafeenko, V. A., Rybakov, V. B., Shokova, E. A. \& Kovalev, V. V. (1987). J. Struct. Chem. USSR, 28, 243-251.

Rieger, B., Abu-Surrah, A. S., Fawzi, R. \& Steiman, M. (1995). J. Organomet. Chem. 497, 73-79.

Rontoyianni, A. \& Mavridis, I. M. (1994). J. Incl. Phenom. Mol. Recognit. Chem. 18, 211-227.

Schomaker, V. \& Marsh, R. E. (1979). Acta Cryst. B35, 1933-1934.

Selent, D. \& Ramm, M. (1995). J. Organomet. Chem. 485, 135-140.

Shibahara, T., Sakane, G., Naruse, Y., Taya, K., Akashi, H., Ichimura, A. \& Adachi, H. (1995). Bull. Chem. Soc. Jpn, 68, 2769-2782.

Shima, K., Kimura, J., Yoshida, K., Yasuda, M., Imada, K. \& Pac, C. (1989). Bull. Chem. Soc. Jpn, 62, 1934-1942.

Shubnell, A. J., Kosnic, E. J. \& Squattrito, P. J. (1994). Inorg. Chim. Acta, 216, 101-112.

Spek, A. L. (2001). PLATON. Utrecht University, The Netherlands. http://www.cryst.chem.uu.nl.

Steil, P., Nagel, U. \& Beck, W. (1988). J. Organomet. Chem. 339, 111124.

Sysoeva, T. F., Branzburg, M. Z., Gurevich, M. Z. \& Starikova, Z. A. (1990). Zh. Strukt. Khim. 31, 90-94.

Taniguchi, M., Sugita, Y. \& Ouchi, A. (1987). Bull. Chem. Soc. Jpn, 60, 1321-1326.

Tatsumi, K., Tahara, A. \& Nakamura, A. (1994). J. Organomet. Chem. 471, 111-115.

Taube, R., Windisch, H., Maiwald, S., Hemling, H. \& Schumann, H. (1996). J. Organomet. Chem. 513, 49-61.

Taylor, R. \& Kennard, O. (1986). Acta Cryst. B42, 112-120.

Ülkü, D., Huddle, B. P. \& Morrow, J. C. (1971). Acta Cryst. B27, 432436.

Urban, R., Krämer, R., Mihan, S., Polborn, K., Wagner, B. \& Beck, W. (1996). J. Organomet. Chem. 517, 191-200.

Waskowska, A. (1997). Acta Cryst. C53, 128-130.

Wei, P.-R., Wu, B.-M., Leung, W.-P. \& Mak, T. C. W. (1996). Polyhedron, 15, 4041-4046.

Yagyu, T., Aizawa, S. \& Funahashi, S. (1998). Bull. Chem. Soc. Jpn, 71, 619-629.

Yasuda, M., Kuwamura, G., Nakazono, T., Shima, K., Inoue, Y., Yamasaki, N. \& Tai, A. (1994). Bull. Chem. Soc. Jpn, 67, 505510.

Yuranov, I. A. \& Dunaeva, K. M. (1989). Koord. Khim. USSR, 15, 845-847. 